\title{
Inscripciones monumentales del siglo VIII (de Cangas a Pravia)
}

Daniel Rico Camps

Universitat Autònoma de Barcelona

Institut d'Estudis Medieval 
Este trabajo se inscribe dentro de las actividades de los proyectos de investigación El impacto de la arquitectura religiosa en el paisaje urbano y rural del nordeste de Hispania y las Islas Baleares (ss. IV-X d.C.), dirigido por G. Ripoll, MINECO-Ministerio de Economía y Competitividad, Plan Nacional $\mathrm{I}+\mathrm{D}+\mathrm{i}$, $\mathrm{n}^{\mathrm{o}}$ ref. HAR2012-35177/Hist. (fondos FEDER), y "Sacra tempora. Certae aedes". Fuentes epigráficas y textuales sobre espacios de la religiosidad en la Hispania tardoantigua y medieval, dirigido por I. Velázquez, $\mathrm{n}^{\circ}$ ref. FFI20I2-34719.

Resumen: En este artículo se hace un primer balance sobre la recuperación de la práctica epigráfica entre los cristianos de la Península Ibérica tras la invasión musulmana de 711 y se analizan en profundidad las cinco inscripciones más importantes y ambiciosos del siglo VIII —asociadas todas a la familia real asturiana-, tratando de situarlas en su contexto histórico, cultural y político. En primer lugar, se estudia la lápida de consagración de la iglesia de Santa Cruz en Cangas de Onís, encargada por Fávila en 737 y que aquí se interpreta desde una perspectiva litúrgica y en clave redentora, descartándose cualquier tipo de intencionalidad política. Justo lo contrario ocurre con la inscripción de la cripta de Santa Leocadia, atribuida por el padre Fita a Wímara (el hermano de Fruela I brutalmente asesinado por el propio monarca) y cuya realización se enmarca en la violenta lucha entre los dos hermanos por el dominio del territorio ovetense mediante la fundación de casas religiosas, entre

AвтRACт: This article gives a first overview of the recovering of the epigraphic practice among Spanish Christians after the Islamic conquest of 711, and it discusses in depth the most important and ambitious inscriptions of the 8th century -all related to religious buildings and to the royal family of the Asturian kingdom-, trying to place them in their historical, cultural, and political contexts. Firstly, it is analyzed the dedication stone of Santa Cruz in Cangas de Onís, commissioned by Favila in 737. The inscription is interpreted here from a liturgical perspective and in a redemptive sense, discarding any kind of political intention. Precisely the opposite occurs in the inscription of Santa Leocadia, attributed by Father Fita to Wimara, the brother of Fruela I brutaly assassinated by the king himself. The inscription was made in the context of the fierce struggle between the two brothers to dominate the territory of Oviedo through the foundation otras estrategias. La segunda mitad del artículo se dedica a las tres inscripciones de la iglesia de Santianes de Pravia, en las que el autor no ve ninguna razón de peso para deshechar su atribución al rey Silo y retrasar, en consecuencia, la construcción de Santianes al siglo X, como se ha propuesto recientemente. En el caso de confirmarse la adscripción de los tres textos a Silo, estaríamos ante el primer "programa epigráfico» de la España medieval y ante un ciclo equiparable a los coetáneos de Metz y Salerno, escritos ambos por Pablo Diácono y destacados precursores del renacimiento epigráfico que se produciría en Europa hacia el año 800.

Palabras Clave: epigrafía medieval; inscripciones monumentales; arquitectura prerrománica; reino astur; Santa Cruz de Cangas de Onís; Oviedo; Santianes de Pravia; Fávila; Wímara; Silo.

of religious houses, among other strategies. The second half of the article adresses the three inscriptions of Santianes de Pravia, in which the author doesn't see any compelling reason to dismiss their attribution to king Silo and to postpone, accordingly, Santianes construction to the 10th century, as recently proposed. In the event of confirming the ascription of the three texts to Silo, we would be facing the first «epigraphic program» of Medieval Spain and a cycle contemporary and comparable to those of Metz and Salerno, both written by Paul the Deacon and outstanding precursors of the epigraphic revival that occurred in Europe around $800 \mathrm{AD}$.

Keywords: Medieval Epigraphy; Monumental Inscriptions; Pre-Romanesque Architecture; Kingdom of Asturias; Santa Cruz in Cangas de Onís; Oviedo; Santianes de Pravia; Fávila; Wímara; Silo 
L

a más antigua inscripción cristiana conservada en la Península Ibérica tras la derrota del ejército visigodo en la batalla de Guadalete es un pobre epitafio de escaso contenido y trémula letra:

\section{$\dagger$ ADULTEUS CLE[RI]CUS V(IXIT) 3 AN(NOS) X R(EQUIE)V(I)T IN P(A)C(E) D(IE) III ED(US) IAN(UARIAS) 6 [ERA] DCCLXVII}

"Adulteo, clérigo, vivió diez años. Descansó en paz el día 3 de los idus de enero de la era 767” (= 11 de enero de 729) ${ }^{1}$.

Fechado, pues, dieciocho años después de la irrupción musulmana y procedente de Mértola y no de Tavira (Faro) como se pensaba hasta ahora, tan misérrimo epígrafe podría tomarse como la más palpable expresión de los estragos que la conquista árabe provocó en el 'hábito epigráfico' de las gentes

Ed. M. M. Alves Dias y C. I. Sousa Gaspar, Catálogo des Inscriçoes Paleocristas do Território Portugês, Lisboa, 2006, pp. 135-6, no 49; calco en IHC 299. Siglas utilizadas: CIL = Corpus Inscriptionum Latinarum; ICERV $=\mathrm{J}$. Vives, Inscripciones cristianas de la España Romana y Visigoda, Barcelona, $1969^{2}$; IHC = A. Hübner, Inscriptiones Hispaniae Christianae, Berlín, I871, y Supplementum, Berlín, I900; IMA = F. Diego Santos, Inscripciones medievales de Asturias, Principado de Asturias, 1994; MGH = Monumenta Germaniae Historica. hispano-visigodas, todavía vigoroso en la segunda mitad del siglo VII².

La interrupción de la producción epigráfica a raíz de la destrucción del regnum visigodo es comprensible y hasta cierto punto comprobable: frente al centenar - como mínimo- de inscripciones fechadas o fechables entre los reinados de Reces-

\footnotetext{
2 A nadie escapa que 'hábito epigráfico' es feliz expresión de MacMullen, "The Epigraphic Habit in the Roman Empire", The American Journal of Philology, I03, (1982), pp. 233-246, que vale la pena leer junto a E. A. Meyer, "Explaining the Epigraphic Habit in the Roman Empire: The Evidence of Epitaphs", The Journal of Roman Studies, 80 (1990), pp. 74-96, y G. Woolf, "Monumental Writing and the Expansion of Roman Society in the Early Empire”, ib, 86 (1996), pp. 22-39. Recientemente se han escrito algunas reflexiones generales sobre epigrafía hispano-visigoda, como J. del Hoyo, "Carmina latina epigraphica de época visigoda", en En la pizarra. Los últimos hispanorromanos en la Meseta, catálogo de la exposición, Burgos, 2005, pp. 69-85; I. Velázquez, "El acto epigráfico en la Hispania visigoda (del rey abajo, todos)", en Hispania Gothorum. San Ildefonso y el reino visigodo de Toledo, Toledo, 2007, pp. 87-106, y "Epigrafia en la Hispania de época visigoda: nuevas perspectivas, revisiones críticas y estudios", en C. Codoñer y P. Farmhouse Alberto (eds.), Wisigothica. After M. C. Díaz y Díaz, Florencia, 20I4, pp. 307-328; J. de Santiago Fernández "El hábito epigráfico en la Hispania visigoda”, en J. C. Galende Díaz y J. de Santiago Fernández (dirs.), VIII Jornadas Cientificas sobre Documentación de la Hispania altomedieval (siglos VI-X), Madrid, 2009, pp. 29I-344; e S. Iranzo Abellán, "Inscripciones métricas", en C. Codońer (coord.), La Hispania visigoda y mozárabe. Dos épocas en su literatura, Salamanca, 20Io, pp. 387-395. Especialmente centradas en las vinculaciones entre epigrafía y arquitectura, cf. I. Velázquez, "Baselicas multas miro opere construxit (VSPE, 5.I.I El valor de las fuentes literarias y epigráficas sobre la edilicia religiosa en la Hispania visigoda", Hortus Artium Medievalium, I3 (2007), pp. 26I268; H. Gimeno Pascual, "El hábito epigráfico en el contexto arquitectónico hispánico del siglo VII”, en L. Caballero Zoreda et al. (coords.), El siglo VII frente al siglo VII. Arquitectura (Visigodos y Omeyas, 4), Madrid, 2009, pp. 3I-44; y D. Rico Camps, "Arquitectura y epigrafía en la Antigüedad Tardía. Testimonios hispanos”, Pyrenae, 40/I (2009), pp. 7-53.
} 
vinto (649-672) y Witiza (698-710), en los casi cien años que corren del 711 al 800 sólo me consta la existencia en la Península de ocho o nueve inscripciones cristianas además de la portuguesa de Adulteo $^{3}$. La interrupción, sin embargo, fue mucho más completa y duradera en las comunidades mozárabes de Al-Andalus que en los territorios cristianos del norte, como parece razonable pensar si tenemos en cuenta que todas las inscripciones del siglo VIII pertenecen al reino astur y su entorno excepto la portuguesa de Mértola y otra, cordobesa, que podría datarse en el año 762 con la misma arbitrariedad que en 961 o cualquier fecha intermedia ${ }^{4}$. Aunque en materia epigráfica no es

\footnotetext{
${ }^{3}$ Estas cifras, basadas en un cálculo personal e insuficiente, coinciden sustancialmente con las que ofrece el gráfico trazado por M. A. Handley, Death, Society and Culture. Inscriptions and Epitaphs in Gaul and Spain, $A D$ 300-750, Oxford, 2003, p. I84, fig. I0.2, con casi I20 inscripciones en el período 650-700 y alrededor de 25 entre los años 700 y 800 (la mayoría, me sospecho, de principios del siglo VIII). Incluso suponiendo, con el propio Handley, que "some, even if not many" de las inscripciones datadas en la segunda mitad del siglo VII "could have been raised in the eighth century" (p. 185), el contraste seguiría siendo incuestionable.

${ }^{4}$ Se trata de un fragmento de epitafio episcopal procedente de Lucena cuya fecha, hoy perdida (E. Serrano y R. Atencia, Inscripciones latinas del Museo de Málaga, Málaga, 1980, pp. 59-60, nº 63, lám. LXXXVI), aparece ya mutilada —ERA DCCC[...]— en el calco publicado por C. Rodríguez, Biblioteca universal de la poligrafía española, Madrid, I738, fol. XVIII. Las otras ocho inscripciones a las que me refiero son las conocidas piedras asturianas (cinco en total) de Cangas de Onís, Santa Leocadia y Santianes de Pravia (IMA 8, I75-I77 y 253); dos estelas del año 762, más pobres aún que la de Adulteus, halladas en las localidades del Corgo (Lugo) y Reinavilla (Rioja Alavesa) respectivamente (P. Rodríguez Suárez y M. Vázquez Bertomeu, "De epigrafía medieval lucense: la colección del Museo Provincial”, Boletín do Museo Provincial de Lugo, I2, 2005, pp. I09-II9, y A. Azcárate Garai-Olaun e I. García Camino, Estelas e inscripciones medievales del País Vasco (Siglos VI-XI), I. País Vasco Occidental, Bilbao, 1996, pp. II8-II9, no 3); y la escueta inscripción fundacional de la ermita de las santas Centola y Elena de Siero (Burgos), fechada en 777 según su último editor (Á. Castresana López, Corpus inscriptionum christianarum et mediaevalium provinciae Burgensis (ss. IV-XIII), tesis doctoral, Universidad Autónoma de Madrid, 2014 , pp. $518-523, \mathrm{n}^{\circ} 285$ ). A este pequeńo grupo de textos grabados en piedra habría quizá que añadir alguna de la siguientes composiciones de transmisión manuscrita: el epitafio del rey Rodrigo copiado en las dos versiones de la Crónica de Alfonso III, 7 (ed. J. Gil Fernández, J. L. Moralejo y J. I. Ruiz de la Peña, Crónicas asturianas, Oviedo, 1985, pp. I22-3); la laudatio funebris del abad Ildemundo, copiada en la Anthologia Hispana, pero redactada en forma de epitafio acaso a finales del siglo VIII (IHC 385); y el poema acrotelésico de Ascárico a Tuseredo ( $\mathrm{IHC}_{3} 86$ ), aunque en este caso me cuesta bastante admitir su condición de epitafio — sugerida por Hübner-y más aún la posibilidad de que se llevase a la piedra. Descarto, en cambio, por entero que el supuesto epitafio del rey Mauregato (IMA Add. 3) fuese tal cosa, así como el hipotético carácter epigráfico de la estrofa del himno mozárabe de San Tirso alusiva a la fundación en Toledo de un templo dedicado al santo por el obispo Cixila (IHC 393). Tampoco incluyo el 'epitafio' en piedra del
}

recomendable extraer conclusiones de ningún tipo a partir de estadísticas realizadas sobre el material conservado y, menos aún, de impresiones cuantitativas como la que acabo de aducir, se diría que en este caso los números cantan. De hecho, las cifras de que dispongo respecto a la novena y décima centurias apuntan en la misma dirección. Según Julián González, "de las 27 inscripciones [mozárabes] cuya datación es segura, 4 corresponden al siglo IX [y] 19 al X"5, mientras que en el territorio astur-leonés los números son notoriamente superiores: 30 se sitúan con plena seguridad en la novena centuria, y unas 60 , contando por lo bajo, en la décima ${ }^{6}$.

El origen de tan notoria diferencia entre los cristianos del norte y las comunidades mozárabes obedece a una razón política, sin lugar a dudas. Pues es verdad que la destrucción del reino visigodo truncó las costumbres epigráficas del conjunto de la sociedad, pero el daño ocasionado no fue ni mucho menos tan radical en el único sector de la misma que logró recomponerse casi de inmediato, por lo menos hasta cierto punto. Me refiero, naturalmente, a la monarquía, aunque se trate de aquella monarquía, reducida a la mínima expresión, en la que "primum in Asturias Pelagius regnavit - asegura la Crónica Albeldense (XV, 1) — in Ca-

obispo Odoario († c. 786), dado que no parece anterior al siglo XI (cf. J. M. Anguita Jaén, "Tres inscripciones lucenses más que milenarias: la Lápida de Bretońa, el Acróstico de Odoario y el Disco de Quiroga”, en M. C. Fernández López et al. (eds.), Oh Lux Iberiae. En torno a las letras en la España medieval, Lugo, 2013, pp. 47-73, espec. 64-7). En la región catalana, la primera inscripción medieval de la que tengo noticia, ya desaparecida, remonta al año 8ıร (J. de Santiago Fernández, La Epigrafía latina medieval en los condados catalanes (815-circ.1150), Marid, 2003, p. 294, no 6), dado que el epitafio del legendario Otger Cataló ( $† 764)$, copiado en el siglo XVI, es un falso seguramente del siglo XIII (cf. S. M. Cingolani, ed., Llibre dels reis, Valencia, 2008, pp. 28-38)

5 J. González, "La epigrafía mozárabe: testimonio de una minoría religiosa”, en M. Pérez González (coord.), Actas del III Congreso Hispánico de Latín Medieval: (León, 26-29 de spetiembre de 2001), 2, León, 2002, pp. 74I-752 (749), aunque el número de las pertenecientes al siglo IX debería triplicarse si tenemos en cuenta los epitafios y epigramas de transmisión manuscrita compuestos por Álbaro, Cipriano y Sansón de Córdoba.

${ }^{6}$ Son números obtenidos fundamentalmente a partir del corpus de F. Diego Santos (IMA), al que he sumado unas pocas inscripciones de otras provincias publicadas en el IHC de Hübner y en otros trabajos dispersos. 
nicas annos XVIIII"7. Fuese cual fuese la exacta percepción que Pelayo y sus primeros sucesores tuvieron del reino en ciernes — si vieron en él un verdadero reino o un mero caudillaje militar, como se discute últimamente-, lo que aquí nos interesa es que lo inscribieron desde un principio - a posta o sin apenas darse cuenta- en la línea del pasado visigodo, asumiendo como propios cuantos elementos de la cultura hispana tardorromana les permitieron las posibilidades y circunstancias de cada momento. Thomas Deswarte ha reunido una buena colección de los que ya estarían activos en la etapa anterior a Alfonso $\mathrm{II}^{8}$, a los que aquí es preciso añadir la producción misma de inscripciones o, por lo menos, de determinado tipo de inscripciones, como pone sobradamente de manifiesto, por solitaria que en principio se nos aparezca, la conocida lápida dedicatoria de la iglesia de Santa Cruz en Cangas de Onís, realizada ni más ni menos que en 737, a tan sólo quince o diecinueve años de la batalla de Covadonga. La cronología de la piedra es tan temprana, y su aspecto y contenido tan hispano-visigodo, que no cabe sino aceptar que el rey Fávila (737-739) la encargó con entera naturalidad, en un "acto epigráfico" — como diría Isabel Velázquez- concienzudo y singular, pero solidario con el background cultural y político en el que el rey y su padre se habían formado?

Aunque la inscripción, desaparecida en 1936, habrá sido publicada un centenar de veces, en esta sede es obligado que volvamos a hacerlo. Me atengo en gran medida a la reciente transcripción de A. Arbeiter y S. Noack-Haley, que es la más fiable por estar basada en una reveladora fotografía del Instituto Arqueológico Alemán de Madrid que hasta ahora había permanecido inédita ${ }^{10}$ :

\footnotetext{
${ }^{7}$ Ed. cit., p. I73 (el subrayado es mío).

${ }^{8}$ De la destruction à la restauration. L'idéologie du royaume d'OviedoLeón (VIII - XI siècles), Turnhout, 2003, pp. 50-65.

9 Sobre el visigotismo de Pelayo, cf. J. Montenegro y A. del Castillo, "Don Pelayo y los orígenes de la Reconquista: Un nuevo punto de vista", Hispania, 52, 1992, pp. 5-32, espec. I3-15 y 20-22.

${ }^{10}$ A. Arbeiter y S. Noack-Haley, Hispania Antiqua. Christliche Denkmäler des frühen Mittelalters vom 8. bis ins 11. Jahrhundert, Mainz,
}

[RESUR]GIT EX PRECEPTIS DIVINIS
HEC MACINA SA[CRA] // OPERE
EXIGUO COMTUM FIDELIBUS
VOTIS // PRESPICUE CLAREAT OC
TEMPLUM OBTUTIBUS SACRIS //
DEMONSTRANS FIGURALITER
SIGNACULUM ALME CRUCIS // SIT
XP̄O PLACENS EC AULA SUB CRUCIS
TROPHEO SACRATA // [Q]UAM
FAMULUS FAFFILA SIC CONDIDIT
FIDE PROMTA // CUM FROILIUBA
CONIUGE AC SUORUM PROLIUM
PIGNERA NATA // QUIBUS XPE
TUIS MUNERIBUS PRO HOC SIT
GRATIA PLENA // AC POST UIUS
VITE DECURSUM PRE[V]ENIAT
MISERICORDIA LARGA // HIC
VATE AST[ERI]O SACRATA SU[N]T
ALTARIA CRISTO // DIEI REVOLUTI
TEMPOR[IS] AN[NI] CCC // SECULI
ETATE PORRECTA PER HORDINE[M]
S[E]X[TA] // CURRENTE ERA
SEPTINGENTESIMA SEPTA[GES]I[MA]
QUI[N] // T[A]QUE

"Surge de instrucciones divinas esta construcción sagrada: adornada en su obra con los votos fieles, que este templo santo aparezca brillante a la mirada de Dios. Haciendo gala de mostrar en figura la señal de la cruz salvadora, agrade a Cristo este edificio colocado bajo la protección de la cruz, que su siervo Fávila fundó con fe viva, junto con Froiluba su esposa y las prendas queridas de los hijos de ambos: reciban, oh Cristo, por ello tu gracia repleta de dones tuyos, y tras el paso de esta vida favorécelos con tu generosa misericordia. Aquí por el obispo Astemo [o Asterio] fueron consagrados estos altares a Cristo, a los trescientos días de haberse comenzado el año, en la sexta edad del devenir ordenado del mundo, corriendo la era $775 "$ (= 27 de octubre de 737$)^{11}$.

I999, p. 98 y lám. 7c. La fotografía la publicó al tiempo L. Arias, Prerrománico asturiano. El arte de la Monarquía Asturiana, Gijón, I999, p. 32.

${ }^{11}$ Traducción de M. Díaz y Díaz, Asturias en el siglo VIII. La cultura 
Como bien ha escrito Manuel Díaz y Díaz ${ }^{12}$, estamos ante "toda una muestra de cómo [en Asturias] se mantenía mejor que peor la tradición de los reinos anteriores, dentro y fuera de la Península", reflejada en la reverberación de Draconcio en prolium pignera y de Venancio Fortunato en macina

literaria, Oviedo, 200I, pp. 32-33. En la transcripción de Arbeiter y NoackHaley, los autores ven AST[ER]IO donde me parece más prudente limitarse a leer AST[ERI]O, dado que la supuesta I podría ser el palo derecho de la M de AST[EM]O, que es el nombre que leyó R. Frassinelli en su calco de I868 (publicado en IMA 253). C. M. Vigil tendía a leer Asterio, según confiesa en una carta enviada en septiembre del mismo año a P. Pérez de Sala (M. de la Rasilla y A. González, Comisión de antigüedades de la Real Academia de la Historia. Asturias. Catálogo e Índices, Madrid 2000, p. 28; la carta puede consultarse en $<$ http://bib.cervantesvirtual.com/FichaObra. html?Ref=310I76\&portal=III>), y así transcribió el nombre en su Asturias monumental, epigráfica y diplomática: datos para la historia de la provincia, Oviedo, I887, p. 305 y lám. J, aunque dejando un lugar para "la incertidumbre", tanto en nota a pie de página como en el dibujo que él mismo hizo de la piedra. F. J. Fernández Conde, "Lugares de culto en Asturias durante la época de transición”, Asturiensia medievalia, 7 (1993-1994), pp. 3I-55 (475I), y "Cristianización y simbología del poder en la época de la monarquía asturiana”, en La época de la monarquía asturiana. Actas del simposio celebrado en Covadonga, 8-10 de octubre de 2001, Oviedo, 2002, pp. 263294 (288), ha optado por una tercera posibilidad, Astemio, y ensayado una interpretación del galimatías cronológico de las últimas líneas que me parece tan forzada como inverosímil, entre otras cosas porque no explica cómo hay que entender diei (1. iI) si aceptamos la forma annis en lugar de anni y la relacionamos en consecuencia con $C C C$, de donde resultaría la traducción "en el año 300 de la sexta edad". Pienso que A. Lambert ("Astère (I8)", Dictionnaire d'Histoire et de Geographie ecclésiastiques, IV, París, I930, pp. II63-4) y J. Vives (ICERV 315) demostraron con sobrados argumentos que la fórmula de datación es más clara y sencilla de lo que parece a primera vista, a pesar del error de conjugación que cometió su autor al tomar diei (genitivo/ dativo) como dies (nominativo plural), en concordancia con trecenti (" 300 días del tiempo transcurrido del año"), o como diebus o die (ablativo: "en el día 300 del año...”). Quizá también confundió annis con anni, pero en la laguna que se observa en la fotografía del Instituto Arqueológico Alemán entran dos letras mejor que tres, y no hay que olvidar que en el meticuloso calco de Frassinelli se da la lección gramaticalmente correcta. Es verdad que la ordinatio de las cinco últimas líneas de la lápida presenta ciertas 'anomalías' que contrastan con la regular disposición de todo el texto precedente, pero en ello no veo ningún indicio de "refacción" de la inscripción original, como sugiere Fernández Conde. El notorio ensanchamiento del interletraje de la palabra Cristo al final de la l. Io —y el hecho mismo de que se escriba sin abreviar-, además de tener una función honorífica o simbólica, le da a esa parte del texto un aire conclusivo y marca una frontera con la fórmula de datación. Por otro lado, el largo espacio en blanco al final la línea siguiente nada tiene de extrańo si tenemos en cuenta que se trata del verso más corto del poema (27 caracteres); de hecho, también el de la 1.2 (con 3r letras) se detiene a un buen trecho del margen derecho. Finalmente, parece claro que lo que provocó la brusca interrupción del último verso obligando al lapicida a introducir un renglón suplementario con el feo -taque, no fue otra cosa que el excesivo sangrado de la l. I3, fuese voluntario (con la intención de remarcar el final de la inscripción, cosa frecuente en epigrafía) o forzado (por una ruptura previa de la piedra en la esquina inferior izquierda).

${ }^{12}$ Asturias..., pp. 34-4I y 152. sacra $^{13}$, el uso de vocablos harto conocidos en la epigrafía visigoda (como vates en sentido episcopal, aula, famulus...), la mención de la "sexta edad" y el rodeo artificioso de la datación, la compaginación del texto y el trazo de las letras, su colocación - a la manera de San Juan de Baños_ - "sobre el arco de la capilla" [mayor] de la iglesia original, según la vió Ambrosio de Morales antes de su destrucción en $1632^{14}$, y la propia función de la lápida: celebrar mediante un carmen epigraphicum la construcción y consagración de una iglesia de patrocinio regio en la capital del reino. El "latin wisigothique, pompeux, obscure et barbare" del texto ${ }^{15}$ no debe impedirnos ver - de nuevo con Díaz y Díaz - el carácter "medianamente hábil" del conjunto, "lleno de pretensiones pero nada vulgar", obra de una persona de cultura limitada (quizá el propio Asterio o Astemo, un obispo emigrado de alguna diócesis cercana o lejana) y que sin embargo fue capaz de obtener, en medio de la penuria reinante, una pieza de notable singularidad.

En este ambiente de celebración áulica y litúrgica y de natural aggiornamento (o restauración, en el sentido de reactivación) de la vieja cultura visigoda, los historiadores siguen preguntándose si no existirá también alguna suerte de intencionalidad política, pero no en el sentido triunfalista que implicaría aceptar como verosímil ${ }^{16}$ la leyenda — consignada por Ambrosio de Morales- de que el santuario de Cangas se hizo para guardar aquella "cruz de madera”, caída del cielo, con la que Pelayo ganó en Covadonga y que Alfonso II se llevaría más tarde a Oviedo ${ }^{17}$, sino en el sentido más tenue o preca-

\footnotetext{
${ }^{13}$ Añádase Optaciano Porfirio, Carm. XXIV, 35 (Aeternum salvis signum dat machina sacra), y Sidonio Apolinar, Epist., IV, I8, 3 (Texerat hic primum plebeio machina cultu), en una de las composiciones que le encargó Perpetuo para la nueva basílica de Sant-Martin de Tours.

${ }^{14}$ Viaje de Ambrosio de Morales a los reinos de Leon y Galicia y Principado de Asturias en 1572, ed. E. Flórez, Madrid, 1765, p. 68. También L. A. de Carvallo, Antigüedades y cosas memorables del Principado de Asturias (16I3), Madrid, I695, p. I24.

15 A. Lambert, "Astèr", Dicctionnaire..., p. II64.

${ }^{16}$ A la manera de C. Cid Priego, Arte prerrománico de la monarquía asturiana, Oviedo, 1995, p. 39.

${ }^{17}$ Una leyenda cuyo núcleo original remonta, como mucho, a los tiempos del obispo Pelayo de Oviedo, como sabiamente ha demostrado R. Alonso,
} 
vido apuntado recientemente por algunos autores como Ayala Martínez, Bronisch o Santiago Fernán$\mathrm{dez}^{18}$. El contexto, fundacional y de resistencia, es en verdad sugerente: la iglesia de Cangas debió ser la principal del reino y la primera fundación regia hasta el momento, se consagró con el máximo esplendor pocos meses después de morir Pelayo "in locum Canicas"19 y se dedicó a la Santa Cruz, “advocación religiosa de victoriosas resonancias militares" heredadas de la etapa visigoda ${ }^{20}$. Pero a mí me parece que el texto no dice ni una sola palabra en la que se perciba una tonalidad o voluntad política. La aparición de Fávila cum Froiliuba coniuge ac suorum prolium pignera nata "quizá podría entenderse como expresión de cierto voluntarismo dinástico", comenta Ayala con razón, pero en ningún momento se alude al padre y predecesor Pelayo, recién fallecido y verdadero artífice del nuevo destino de su familia frente al parco legado del heredero, al que ni la Cronica Albeldensia ni la redacción Ad Sebastianum de la de Alfonso III atribuyen ningún suceso digno de mención ${ }^{21}$. Y es la iglesia — denominada con redundante insistencia macina sacra, templum, aula y altaria-, y no la patria o el reino, lo que el monarca pone, en tanto que siervo de Dios (famulus Faffila), bajo la protección de la cruz (sub crucis tropheo sacrata), una iglesia fundada "con una fe manifiesta" ( fide promta) en la cualidad "salvadora" o "vivificadora" de la señal de la cruz (signaculum

\footnotetext{
"El origen de las leyendas de la Cruz de los Ángeles y la Cruz de la Victoria (catedral de Oviedo): cruces gemmatce al servicio de la propaganda episcopal", Territorio, Sociedad y Poder, 5 (2010), pp. 23-33 (32-33).

${ }^{18}$ C. de Ayala Martínez, Sacerdocio y Reino en la España Altomedieval. Iglesia y poder politico en el Occidente pensinsular, siglos VII-XII, Madrid, 2008, pp. I07-I08; A. P. Bronisch, Reconquista y guerra santa, La concepción de la guerra en la España cristiana desde los visigodos hasta comienzos del siglo XII, Granada, 2006, p. 4IO; y J. de Santiago Fernández, "Las Inscripciones Medievales: documentos al servicio del poder político y religioso", en I Jornadas sobre Documentación jurídico-administrativa, económico-financiera y judicial del reino castellano-leonés (siglos $X$ XIII), Madrid, 2002, pp. 93-I28 (99).

${ }^{19}$ Dice la Albeldense (XV, I) y repite la Rotense (II), añadiendo que falleció "morte propria" (ed. cit., pp. 173 y 130).

${ }^{20}$ Ayala, Sacerdocio y Reino..., p. I08.

${ }^{21}$ Esta última lo dice, además, con cierta crudeza, aunque dé sus razones: "qui propter paucitatem temporis nihil istorie dignum egit" (A Sebastián, I2; ed. cit. p. I3I). Sólo la versión Rotense registra que "basilicam in honore sancte Crucis miro opere construxit” (I2, ed. cit., p. 130).
}

alme crucis). Como ha visto García de Castro, en los versos tercero y cuarto se están parafraseando expresiones de la liturgia hispana cuyo marco ritual no es - pongamos por caso- el Ordo quando rex cum exercitu ad prelium egreditur, sino el apropiado a las circunstancias inequívocas que llevaron a encargar la inscripción: la consagración y ofrenda de un santuario. Se trata de fórmulas de conjuro, como las que ritman el Exorcismus ad consecrandum signum basilicae ("sancte crucis signaculo adversus inpugnationes diaboli totus victor muniatur homo"), y de victoria sobre la muerte y el pecado, como las del himno de la cruz que se cantaba el Viernes Santo ("Christus (...) / Per crucis alme tropheum / Lavit omne seculum") o las prescritas para bendecir las cruces votivas que los fieles ofrecían a las iglesias ("consecra tibi munus hoc famuli tui, tropheo scilicet victorie tue, redemtionis nostre") 22 .

Es asimismo en esta línea redentora como creo que hay que interpretar el sentido principal (no necesariamente único) del verbo con el que arranca el poema: resurgere. Su elección en detrimento de variantes de la misma raíz como 'surgere' o 'consurgere' ha dado lugar a traducciones del estilo 'vuelve a levantarse' (Diego Santos) o, literalmente, 'resurge' (García de Castro) y a suponer con ellas que la iglesia de Fávila se concibió como la refundación o reconstrucción de una capilla anterior, fuese un antiguo dolmen cristianizado o todo un templo cruciforme de época visigoda. Ciertamente, resurgere se usó en el sentido indiscutible de reconstrucción desde Numida (CIL VIII, 10707) hasta la propia Asturias (IMA 158), pero el indicio es demasiado débil y sólo la arqueología podrá refrendarlo. En cualquier caso, aun en el caso muy probable de que se restaurase un edificio anterior, lo que no acaba de convencerme es que "la idea de resurgimiento" que encierra la primera palabra de la inscripción quede

\footnotetext{
${ }^{22}$ M. Férotin, Le Liber Ordinum en usage dans l'église wisigothique et mozarabe d'Espagne du cinquième au onzième siècle, París, 1904, cols. I59, I96 y i64, respectivamente. Tomo los paralelos litúrgicos de C. García de Castro Valdés, Arqueología cristiana de la Alta Edad Media en Asturias, Oviedo, 1995, p. 183, y Bronisch, Reconquista y guerra santa..., p. 410.
} 
“inevitablemente vinculada a la embrionaria forma de monarquía encarnada por Fávila” y, por ahí, si entiendo bien las palabras de Ayala, que su figura adquiera "en esta lápida fundacional cierta intencionalidad político-religiosa"23. Que alguna voluntad política hubo podemos sospecharlo, pues eran el rey y su familia quienes actuaban públicamente (re)construyendo la iglesia y quienes aplaudían el acontecimiento con la pompa de un texto de aparato y, por lo tanto, de prestigio y autoafirmación, pero una cosa es lo que está (o se supone) implícito o subyacente en el encargo y otra cosa muy distinta lo que aparece explícito en la inscripción (y que conforma el mensaje definitivo y estable que se quiere transmitir), y en la inscripción de Cangas la dimensión política brilla por su ausencia para concentrar exclusivamente la atención en los aspectos espiritual y litúrgico de la celebración.

El comienzo es ciertamente imponente: Resurgit ex preceptis divinis hec macina sacra, sobre todo para quien entreoyese en la palabra macina el eco de su acepción bélica (acaso más expandida entonces que la religiosa de Venancio Fortunato) ${ }^{24}$, pero lo que en seguida percibiría ese mismo lector es que el ingenio que 'se elevaba' o 'volvía a elevarse' en el lugar de Cangas era un edificio sagrado puesto bajo el signo protector y reparador de la cruz; más aún, un edificio que se identificaba figuraliter — literal o simbólicamente - con la propia señal de la cruz redentora, como en la célebre inscripción de San Ambrosio - Forma crucis, templum est, templum victoria Christi: / sacra triumphalis signat imago locum (CIL V, p. 617, 3)—, lo que llevaba a asimilar

\footnotetext{
${ }^{23}$ Desde luego, la caracterización de famulus no la revela en absoluto, por mucho que más adelante la utilizase "el indiscutible forjador de la monarquía asturiana, Alfonso II” (Ayala, Sacerdocio y reino..., pp. I07-I08), pues el adjetivo gozó de una extraordinaria difusión en la epigrafía cristiana de la Antigüedad Tardía (F. Grossi Gondi, Trattato di epigrafia cristiana latina e greca del mondo romano occidentale, Roma, 1920, p. 160), especialmente en Hispania (M. T. Muñoz García de Iturrospe, Tradición formular y literaria en los epitafios latinos de la Hispania cristiana, Vitoria, 1995, pp. 93-96).

${ }^{24}$ El vocablo ni siquiera se contempla en el capítulo relativo a la terminología basilical en las inscripciones tardorromanas de P. de Santis, Sanctorum monumenta. 'Aree sacre' del suburbio di Roma nella documentazione epigrafica (IV-VII secolo), Baris, 2010, pp. I03-166.
}

de inmediato el (re)surgimiento del templo con la resurrección de Cristo, de forma parecida a como lo hacía otra famosa inscripción ambrosiana en $\mathrm{Mi}$ lán: Octachorum sanctos templum surrexit in usus / octaganus fons est munere dignus eo. / Hoc numero decuit sacri baptismatis aulam / surgere, quo populis vera salus rediit / luce resurgentis Christi, qui claustra resolvit / mortis et e tumulis suscitat exanimes (CIL $\mathrm{V}$, p. 617, 2), donde queda claro que el templo $s u$ rrexit para devolver a los pueblos la salvación de Cristo resurgentis. Esta es la clave, a mi entender, de la elección y colocación de resurgit al comienzo del texto asturiano ${ }^{25}$, un verbo que en su sentido dogmático y espiritual tuvo mayor predicamento, como es lógico, en la epigrafía funeraria que en la monumental ${ }^{26}$. El cuarto verso del poema (demonstrans figuraliter signaculum alme crucis) se ha traducido e interpretado de muchas maneras, pero lo que no admite dudas es que se inscribe en un contexto simbólico en el que el poeta nos invita a asimilar la iglesia a la cruz y a descubrir en la restauración del edificio la renovación del misterio de la resurrección del Señor y la esperanza en la salvación, al igual que en los carmina ambrosianos o en el verso de Optaciano Porfirio anteriormente citado (supra, n. 13).

Fávila pudo perfectamente vincular para sus adentros, $\mathrm{o}$ incluso en arenga ante sus gentes el día de la consagración, la promoción de la iglesia regia con la afirmación de la monarquía (por muy embrionaria que fuese su naturaleza), así como la dedicación a la Santa Cruz con su exaltación en el campo de batalla, pero en la inscripción estas asociaciones no aparecen por ninguna parte. En ella,

\footnotetext{
25 Como ya sugirió, en cierta forma, G. Sanders, Lapides memores Païens et chrétiens face à la mort: le témoinage de l'éoigraphie funéraire latine, Faenza, I99I, p. 27I, y opina Deswarte, De la destruction...., p. 3I2, que no duda en traducir "cet édifice sacré ressucita conformément aux préceptes divins" (el subrayado es mío).

${ }^{26}$ Cf. Sanders, Lapides memores..., espec. 245-6; F. Gilsanz Stanger, "La poesía de Sedulio y Eugenio de Toledo en dos inscripciones hispanas del siglo VII". Cuadernos de Filología Clásica. Estudios Latinos, 25.2 (2005), pp. 6784 (7I-72), y A. Mastino, "La Risurrezione della carne nelle iscrizioni latine del primo cristianesimo", en Morte-risurrezione nei Padri della Chiesa, Roma, 2007, pp. 289-332 (espec. 3IO, donde el autor también interpreta el resurgit de nuestra inscripción "con riferimento alla croce di Cristo").
} 
Fávila ni siquiera recibe el título de rex o princeps ${ }^{27}$. El poeta lo presenta simplemente como siervo de Dios cuya viva fe (fide promta) y el sometimiento a los preceptos divinos (ex preceptis divinis) le han llevado a él y a su familia a fundar un sencillo edificio (opere exiguo) cuyo único valor $-\mathrm{y}$ la exclusiva razón por la que se pide la aprobación de Cristo- es el adorno que le infunden los votos $\mathrm{u}$ ofrendas de los fieles (comtum fidelibus votis) y su consagración a la Cruz salvadora (perspicue clareat... demontrans..., sit Christo placens sub crucis...). La piadosa ofrenda se cierra con una cláusula de intercesión que no en balde culmina con la petición de la misericordia divina para Fávila y su familia después de la muerte (post uius vite decursum).

Para captar mejor la naturaleza sustancialmente religiosa $-o$, si se quiere, la cautela políticade la lápida de Fávila quizá no sea desacertado compararla con las dos inscripciones dedicatorias escritas por las mismas fechas para conmemorar la fundación — poco después de 729- del conjunto palacial y monástico de Corteolona por el poderoso rey Liutprando (MGH Poet. I, pp. 105106). En una de ellas, el monarca nos narra en primera persona la revelación que tuvo en Roma al besar la cabeza de San Anastasio y que le llevó a construir, en lugar de unos baños reales, una iglesia repleta de marmora y columnas en honor del santo. Liutprando se imagina a sí mismo en el templo alzando las manos al cielo (meas tendens ad sidera palmas) para suplicar a Cristo que acreciente en él la fe católica (ut crescat mecum catholico ordo) y favorezca a su iglesia del mismo modo que le fue prometido a Salomón (et templo concede iste ut Salomoni locutus). La asociación con el rey de Israel y la afirmación de la imagen de Liutprando "as the mediating instrument of

\footnotetext{
${ }^{27}$ Rompiendo en este punto con la tradición visigoda de inscripciones regias, en que la titulatura se diría preceptiva. $V$. gr., el devotus ego rex Reccesvinthus de San Juan de Baños, el rex inclytus... Wamba de las murallas de Toledo o la fórmula 'nombre + rex + offeret' en las coronas de Guarrazar (ICERV 36I, 3 I4 y 375-376).
}

the divine for his people and as guardian of the faith" 28 marcan con nitidez la enorme distancia que separa la actitud del monarca longobardo de la del rey astur. El contraste salta aún más a la vista en la otra inscripción, que se presta mejor a la comparación con la de Cangas en la medida en que se estructura de forma parecida, con la diferencia, no obstante - y el dato es igualmente revelador-, de que la longobarda no incluye la cláusula de consagración con la que concluye la asturiana. Primero se presenta el edificio sagrado, señalado como domus Domini, pero embellecido, no por el brillo de su advocación sagrada — que ni siquiera llega a mencionarse-, sino por el fulgor de los materiales con los que había sido levantado, importados directamente de Roma (marmora cui pretiosa dedit museumque columnas / Roma...). A continuación se introduce, como en Cangas, el recuerdo del promotor, pero con el título - esta vez sí- de princeps y como autor de una obra sagrada (auctor sacri laboris) cuya evocación tampoco le sirve al poeta para atraer hacia el monarca la gracia divina como en el caso de Fávila, sino para proclamar la larga fortuna de sus gestas (te felicem tua clamabunt acta per aevum) y recordar los triunfos de su pueblo (proprie gentis trimphos).

Poco era lo que tenían en común el potente estado de Liutprando y el frágil dominio de Fávila, y pecisamente por eso en nada se parecen sus respectivos poemas conmemorativos a pesar de pertenecer al mismo género epigráfico -áulico y fundacional—, de ser rigurosamente contemporáneos y de mostrarnos ambos la devota generosidad de un príncipe. Las inscripciones de Corteolona «are two examples of how Liutprand was using epigraphy as a means of royal propaganda $»^{29}$. En ellas, la imagen del nuevo Salomón y la gloria de sus gestas ocupan un lugar tan eminente como la iglesia de San Anastasio. En Cangas, Fávila, Froiluba y sus hijos también ocupan espacialmente el centro de la

\footnotetext{
${ }^{28}$ N. Everett, Literacy in Lombard Italy, c. 568-774, Cambridge, 2003, p. 250.

${ }^{29}$ Ib. p. 253.
} 
inscripción, pero en una posición de total entrega a la causa sagrada y de sujeción al imperio protector de la Cruz. El centro de la atención es en realidad la macina sacra — templum, aula, altaria - que recorre el texto de principio a fin, la sacralidad de la obra, subrayada por el poeta con insistente paronomasia ("sacra, sacris, sacrata se dice respectivamente del edificio, de sus objetivos, y del hecho posterior de la consagración") ${ }^{30}$, asemejando su restauración a la redención operada por Cristo. La lápida se creó en un ambiente cortesano que a lo mejor estaba viviendo un cierto momento de satisfacción ideológica y militar, pero este estado de ánimo que podría calificarse de político-religioso y hasta explicar el propio acto epigráfico - la decisión de celebrar en piedra la consagración de la iglesia-, en la inscripción no aparece reflejado por ninguna parte.

Para encontrar la más antigua inscripción asturiana con un más que presumible acento político tenemos que viajar hasta el reinado de Fruela I (757768), el hijo y sucesor de Alfonso I, y detenernos en la espectacular lápida de granito que en 1898 apareció reutilizada como material de relleno en el macizo de la mesa de altar de la cripta de Santa Leocadia, en la Cámara Santa de la Catedral de Oviedo (Fig. 1). Su estado fragmentario impide asegurar si el letrero terminaba en la cuarta línea y nos oculta dos detalles fundamentales: el destino y el promotor exactos de la pieza. Sin embargo, la parte conservada es suficiente para entender que estamos ante otro poema fundacional y principesco del que además, a diferencia del de Fávila, todos los editores han alabado la calidad de los hexámetros:

\section{$†$ PRINCIPUM [EGR]EGIUS HANC AULAM VV[IMARA FECIT] // HEC ORE HOC MAG[NO] EXIMIA MACINA [---] // UNDIVAGUMQUE MARIS PELAGUM HABIT[---] // HAULA TENET HOMINES INMENSO [--- $]^{31}$}

\footnotetext{
${ }^{30}$ Díaz y Díaz, Asturias..., p. 37, n. 58.

${ }_{31}$ Díaz y Díaz, Asturias..., p. 44, ensaya en la medida de lo posible la siguiente traducción: "Egregio entre los príncipes, este templo [lo construyó
}

No es necesario entretenernos ahora en las conjeturas de Fita, Bücheler y Hübner sobre las cláusulas perdidas de los renglones 2-4, ni en sopesar si la eximia macina sobre cuya gran boca o entrada (ore magno) debió campear la inscripción sería un asilo para marinos, una fortaleza, un hospicio de peregrinos o un monasterio designado metafóricamente como puerto seguro contra las tempestades del mundo ${ }^{32}$. Me interesa tan sólo que nos fijemos en la verosímil reconstrucción del primer verso con un fecit final, en el que coinciden todos los editores y que prácticamente obliga a interpretar la doble $\mathrm{V}$ como inicial del nombre del enigmático "príncipe" que encabeza el letrero, y que atendamos asimismo a una importante pareja de indicios: la paleografía sitúa la inscripción con considerable fiabilidad en los siglos VIII o IX ${ }^{33}$, y la historia nos asegura que en aquellos tiempos el título de princeps era exclusivo del soberano o monarca, fuese por derecho o por usurpación ${ }^{34}$. Con esta argumentación de base, el Padre Fita descartó que el sujeto del primer verso fuese el Vulfila estimado por Hübner, dado que "ningún rastro queda de semejante príncipe o soberano" en Asturias, y tanteó la atractiva posibilidad de que se tratase de Wimara, un hermano de Fruela I del que sólo sabemos que fue violentamente asesinado por el propio rey ("fratrem suum nomine Vimaranem propriis manibus interfecit", dicen las dos versiones de la Crónica de Alfonso III, 16) a

\footnotetext{
Vímara]. Con esta gran entrada esta insigne construcción [---] y esta iglesia retiene el undoso piélago del mar en su inmenso [---]". Mag[no] y VV [imara fecit] son puras conjeturas, la primera debida a Hübner ("Nouvelle inscription métrique, du VIII ${ }^{\mathrm{e}}$ siècle, trouvée à Oviedo", Bulletin Hispanique, 1 (1899), pp. 204-7), y la segunda, a F. Fita, "La insigne lápida de Oviedo", Boletín de la Real Academia de la Historia, XXXVIII (I90I), pp. 35-48 (espec. 45-6), quien también propuso la lección hecore (=aequore) en el arranque de la 1. 2, donde la notable habilidad métrica del autor aconseja leer hec ore.

${ }^{32}$ Que a mi juicio es la hipótesis más plausible, defendida por Díaz y Díaz, Asturias..., p. 46. El mero hecho de que el aula al que estaba destinado el epígrafe también se denomine macina, como en la inscripción de Fávila, parece ya un indicio revelador de la sacralidad del lugar.

${ }^{33}$ Cf., especialmente, IHC 484; F. Fita, "La insigne lápida...", p. 44; y García de Castro, Arqueología cristiana..., pp. I05-I06.

34 Sobre la identidad y simultaneidad de los términos princeps y rex en las fuentes hispanas desde época visigoda, cf. Deswarte, De la destruction..., pp. 52-5.
} 


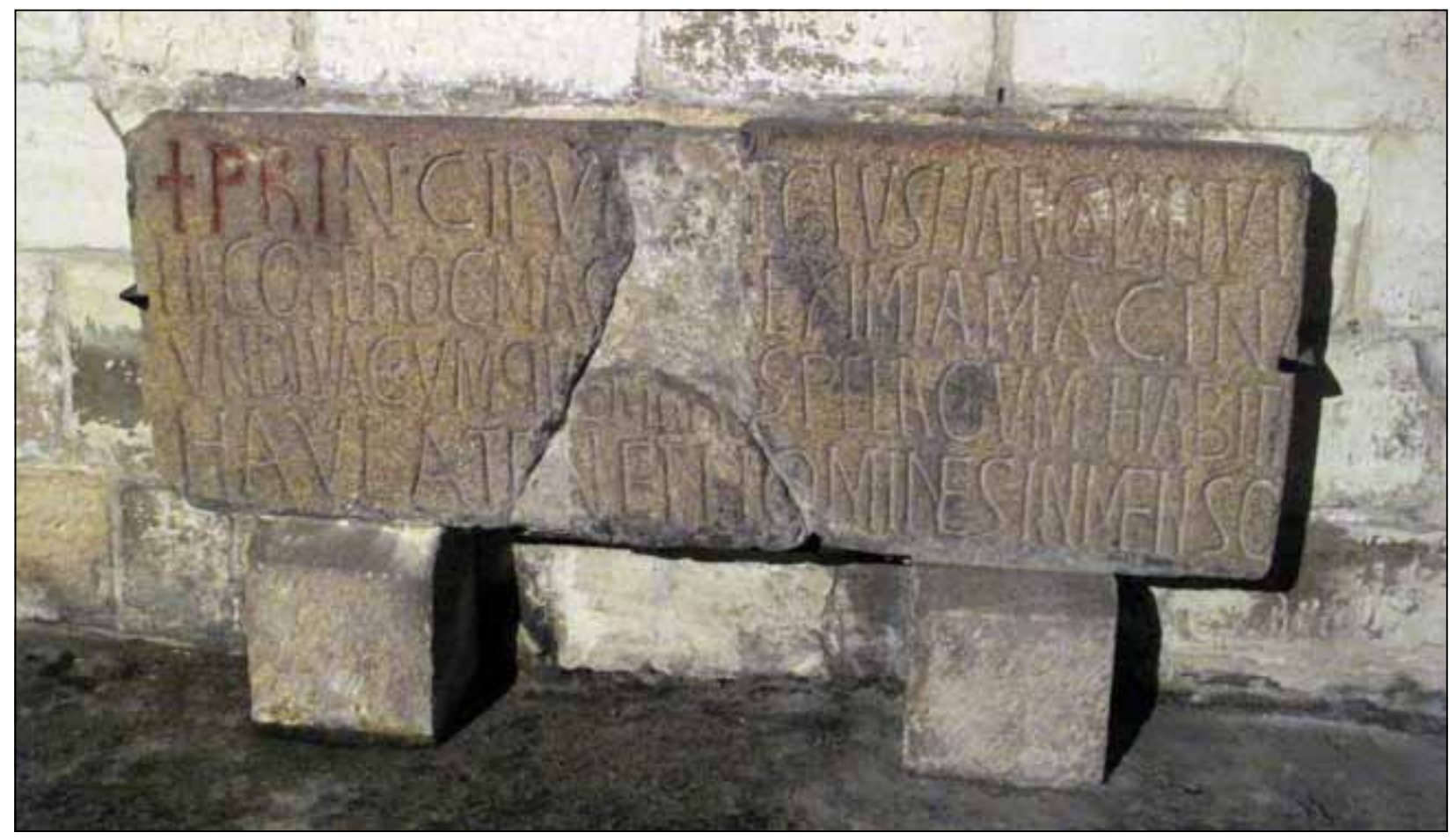

Fig. I - Inscripción atribuida a Wímara, Catedral de Oviedo, cripta de Santa Leocadia.

causa de disputas por el trono ("ob invidia regni", precisa la Albeldense, XV, 4$)^{35}$.

La explicación de Fita no ha encontrado de momento ninguna rival capaz de rebatirla y suplantarla. Díaz y Díaz la aceptó como "altamente verosímil, por no decir del todo segura”, ampliándola con una observación que merece tenerse en cuenta: si Wímara tuvo la osadía de adueñarse del título de princeps mediante un texto público como el que nos ocupa y, más aún, de encuadrarse en una serie de legítimos soberanos con un superlativo "el más egregio de los príncipes", quiere esto decir que su intento de arrogarse el trono fue serio y, por lo tanto, intolerable para su hermano, que lo vería como un delito de lesa majestad que explicaría el consiguiente fratricidio ${ }^{36}$. Sugirió asimismo que la inscripción habría sido trasladada a Oviedo como "pieza de

\footnotetext{
${ }^{35}$ Ed. cit., pp. 134-I35 y 174.

${ }^{36}$ Asturias... pp. 47-9.
}

convicción" 37 , y "que ya en su tiempo fuera sometida a una especie de damnatio memoriae con el corte marginal [limpio y deliberado] que liquidaba definitivamente el nombre y recuerdo del pretendido usurpador"38.

Que el destino de la piedra fuese algún edificio de Oviedo o su entorno resulta coherente, en la medida en que tal fue el lugar donde se reutilizó en la Edad Media y se halló en la moderna. Y que Wímara tuviese intereses en el locum Oveto dice bien con la actividad que sabemos que allí desplegó su hermano Fruela, al fundar las primitivas iglesias de San Salvador y de los mártires Julián y Basilisa ${ }^{39}$. Isabel

\footnotetext{
37 Como ha visto García de Castro, Arqueología cristiana..., p. Ior, al ser la lápida de granito, piedra inexistente en el centro de Asturias, es factible que viniese del macizo galaico-portugués, donde Fruela tuvo que sofocar una rebelión de la nobleza (Crónica de Alfonso III, i6; ed. cit., pp. 134-5) y donde el recuerdo de Wímara se ha querido ver en topónimos como Guimarán (F. de Seglas, Monumentos Ovetenses del siglo IX, Madrid, I908, p. 60).

${ }_{38}$ Asturias..., p. 5I.

${ }^{39}$ Como es bien sabido, la noticia sobre las construcciones de Fruela en
} 
Torrente ha planteado la posibilidad de que Fruela se dirigiese a la colina ovetense con la esperanza de obtener el perdón por el fratricidio cometido y alcanzar así la rehabilitación política, al menos para su hijo Alfonso ${ }^{40}$. La elección del lugar pudo deberse tanto a su asociación con el monasterio de San Vicente, foco de vida religiosa desde principios de los años sesenta, como a su estrecha vinculación con el propio Wímara, que podría haber tenido propiedades en la zona y haber ejercido algún tipo de dominio sobre ella ${ }^{41}$. A no ser que la presencia de los dos hermanos en Oviedo y, en general, en el área central de la región astur transmontana coincidiese en el tiempo y debamos interpretarla como un episodio crucial de sus rivalidades en torno al reino. Dicho de otro modo: que extender el poder al territorio ovetense -o fortalecerlo, si ya tenían algún control sobre el lugar - entrase en los planes políticos de ambos y que los dos recurriesen a la fundación de instituciones religiosas "como el medio más efectivo para hacer realidad su proyecto" ${ }^{\prime 2}$. En tal escenario,

Oviedo las conocemos tan sólo a través de dos textos asociados a Alfonso II y la basílica del Salvador: las dos lápidas fundacionales del altar mayor, que nos han llegado a través de la transcripción del obispo Pelayo en el Liber Testamentorum, fol. I (cf. IMA 6, y la ed. de M. Josefa Sanz Fuentes, Liber Testamentorum Ecclesiae Ovetensis, Barcelona, 1995, p. 455), y la célebre donación del año 812 (S. García Larragueta, Colección de documentos de la Catedral de Oviedo, Oviedo, I962, pp. 4-9, n 2), cuya autenticidad ha generado un amplio debate, del que ofrecen un completo y conciso resumen bibliográfico J. Montenegro y A. del Castillo, "The Alfonso II Document of 812, the Annales Portugalenses Veteres and the Continuity of the Visigothic Kingdom of Toledo as the Kingdom of Asturias", Revue Belge de Philologie et d'Histoire, 87 (2009), pp. 197-214 (197-200).

40 “Sedes regias de la monarquía asturiana”, en M. I. Loring García (ed.), Historia social, Pensamiento historiográfico y Edad Media. Homenaje al Prof. Abilio Barbero de Aguilera, Madrid, 1997, pp. 575-59I (585-7).

${ }^{41}$ Pensemos que los descubrimientos arqueológicos de los últimos años certifican una considerable ocupación de Oviedo y su entorno en época antigua y tardoantigua que justificaría su pronta reocupación y asentamiento en el siglo VIII. Cf. J. A. Gutiérrez González, "Oviedo y el territorio astur entre Mahoma y Carlomagno (siglos VII-IX)”, en De Mahoma a Carlomagno. Los primeros tiempos (siglos VII-IX). XXXIX Semana de Estudios Medievales, Estella, 17-20 julio 2012, Pamplona, 2013, pp. 377-434 (410-423). Antes de Alfonso II, se observa una reveladora coincidencia entre la ubicación de las distintas cortes y fundaciones eclesiásticas de patrocinio regio y los territorios en los que los monarcas poseían haciendas y arraigo entre las élites locales (cf. M. Calleja Puerta y S. Beltrán Suárez, "El espacio centro-oriental de Asturias en el siglo VIII", en La época de la monarquía..., pp. 63-109).

${ }^{42}$ F. J. Fernández Conde et al., "Poderes sociales y políticos en Asturias. Siglos VIII-X", Territorio, Sociedad y Poder, Anejo no 2 (1999), pp. II-30 (25). la eximia macina erigida por Wímara formaría parte de su estrategia de apropiación de la dignidad regia, y lo mismo cabría decir, en igual o mayor medida, de la lápida que la encabezaba, al arrebatarle a Fruela - y desde la primera palabra — ni más ni menos que la titulación. No olvidemos que Fruela pudo ser el primero de los soberanos asturianos en recibir el título formal de rex, a juzgar al menos por el conocido pacto monástico de San Miguel de Pedroso ${ }^{43}$. Es verdad que la temprana datación de dicho documento en el año 759 está sujeta a la polémica, pero no es menos cierto que Fruela volvería a recibir el apelativo de princeps en la inscripción dedicatoria de San Salvador de Oviedo y que la titulación regia parece haberse asentado definitivamente en Asturias con los monarcas sucesivos ${ }^{44}$.

En el caso de que la identificación con Wímara fuese correcta, la inscripción de Santa Leocadia no sólo sería el más antiguo testimonio — de autenticidad indiscutible - de la adopción del título de princeps en el reino astur, sino un ejemplo extraordinario de la utilización política de la epigrafía en los albores de la España medieval. La comprobación definitiva difícilmente llegará a producirse si no se verifica antes un milagroso hallazgo arqueológico que nos devuelva al presente el nombre perdido $y$, a todas luces, mutilado de la piedra. Pero de momento tenemos una hipótesis cabalmente construida a partir de la admirable intuición del Padre Fita y una lápida cuya propia arrogancia parece abundar en esa dirección. Pues no es sólo que la inscripción tilde a su protagonista como principum egregius, sino que la exageración o lo superlativo parecen determinar el conjunto del texto, donde todo se señala gigantesco (ore hoc magno, hec eximia machina, inmen-

\footnotetext{
43 Celebrado en presencia "gloriosi Froilani regis" (A. C. Floriano, Diplomática española del periodo astur: estudio de las fuentes documentales del Reino de Asturias (718-910), I, Oviedo, I910, no 7, pp. 59-60).

${ }^{44} \mathrm{Nada}$ consta en el caso del rey Aurelio, pero sí de Silo, llamado princeps en el famoso laberinto de Santianes y en el pacto de San Vicente de 78I, as como de Mauregato, en el acróstico del himno O Dei Verbum (O rex regum, regem piium Maurecatum aexaudi...), y de Vermudo I, en el pacto de Aquas Calidas de 790 ("rege Vermudo in Asturias"). Recoge todas estas noticias, J. I. Ruiz de la Peńa Solar, "La realeza asturiana y la formulación del poder regio", en La época de la monarquía..., pp. I63-2II (I75-7).
} 
so... $\left.{ }^{45}\right)$, y hasta extenderse al propio formato de la lápida, que — completa - debió alcanzar los 170 $\mathrm{cm}$. de ancho (por 50 de alto) y cuyas letras miden unos $10 \mathrm{~cm}$. de altura aproximadamente, todo en extremado contraste con la humilde piedra de Fávila, con un poema mucho más extenso ocupando un campo la mitad de estrecho (68 x $89 \mathrm{~cm}$.). El solo hecho de que las dos palabras más importantes de la lápida — principum y haula—, no en vano colocadas al principio de la primera y la última líneas respectivamente, se escribieran con un interletraje y un ancho de letra mayores que todas las demás es un revelador indicio de la vocación simbólica $-\mathrm{y}$, aquí sí, política- de la pieza ${ }^{46}$.

Si pudiésemos imaginar a un Fruela I vencedor en la cumbre ovetense sobre las intrigas de su hermano, no sería descabellado suponerlo, asimismo, rematando allí su venganza con la destrucción de la macina de Wímara y la condenación — pública y ritual— de su nombre en la lápida. Pero las crónicas dicen que el feroz monarca murió "in Canicas" (Albeldense, XV, 4 ), asesinado por los suyos, poco después del fratricidio - "qui non post multum temporis talionem excipiens a suis interfectus est" (A Sebastián, 16, 11-2). $\mathrm{Y}$ todo viene a indicar que, con el desplazamiento a Pravia de la sede regia a partir de Silo, Oviedo desapareció del mapa político asturiano hasta la elevación al trono de Alfonso II prácticamente un cuarto de siglo después. Se diría, pues, que quien en verdad tuvo la oportunidad $-\mathrm{y}$ verdadera necesidad- de borrar las huellas de Wímara en Oviedo fue el propio hijo de Fruela, quien siendo todavía niño había tenido que huir de la tierra que lo vio nacer y renacer en el bautismo ("in hoc loco qui nuncupatur Ovetdao... quo solus natus locoque renatus") a causa de las encarnizadas luchas por el poder que entonces se desataron entre las distintas ramas de su familia y que, tras largos ańos desposeído del trono, en cuanto

\footnotetext{
45 Inmenso culmine surgens, proponía Bücheler (según Hübner, "Nouvelle inscription...,", p. 207).

${ }^{46} \mathrm{La}$ cruz inicial y las tres primeras letras de principum parecen rubricadas, aunque me sorprende que el color haya desparecido completamente en el resto de la inscripción. Sin una autopsia de la pieza no me atrevo a decir más.
}

las circunstancias políticas se lo permitieron, concibió y, a ciencia cierta, escenificó su regreso "in proprio patrio domo", y la consiguiente reconstrucción de la basílica de San Salvador, a imagen y semejanza del patriarca Jacob siendo conducido por Dios "in terram nativitatis sue" y, allí, "altari constructo tibi [Domino] munera offerre" ${ }^{\text {" }}$. Para aquel Alfonso que había sido apartado sucesivamente del poder por toda su parentela, la restauración de Oviedo significaba también la reparación de la memoria dañada de su padre. No de otra forma debe entenderse el extenso recuerdo que le dedicó en la inscripción perdida de la basílica del Salvador, cuya columna del Evangelio empezaba así:

\section{QUICUMQUE CERNIS HOC TEMPLUM DEI HONORE DIGNUM, / NOSCITO HIC ANTE ISTUM FUISSE ALTERUM HOC EODEM ORDINE SITUM / QUOD PRINCEPS CONDIDIT SALVATORI DOMINO SUPPLEX / PER OMNIA FROILA DUODECIM APOSTOLIS DEDICANS BISSENA ALTARI / PRO QUO AD DEUM SIT VESTRA CUNCTORUM ORATIO PIA, / UT VOBIS DET DOMINUS SINE FINE PREMIA DIGNA.}

"Quienquiera que contemples este templo digno del honor de Dios, sábete que antes hubo aquí otro dispuesto en este orden, que fundó en honor de San Salvador el príncipe Fruela, todo suplicante, dedicando a los apóstoles seis y seis altares. Por él se eleve la oración piadosa de todos, para que os dé el Señor la digna recompensa sin fin”, ${ }^{\text {\% }}$.

\footnotetext{
47 Me hago eco de las propias palabras del monarca en el Testamentum regis Adefonsi, donde la comparación no puede ser más explicita: "Et nos pie dignatus es de multis tribulationibus ervendo in proprio patrio domo reducere sit munus hoc tibi acceptum sicut accepta munera predicti Iaocb pueri tui..." (ut supra, n. 39). Cf. Torrente, "Sedes regias...", p. 58I, y "La Corte de Oviedo", en Orígenes. Arte y cultura en Asturias. Siglos VII-XV, Oviedo, I993, pp. II5-9 (II5-6).

${ }^{48}$ Ed. y trad. de Díaz y Díaz, Asturias..., p. 134.
} 
La vindicación de Fruela frente a la damnación de Wímara: una inscripción por la otra. La posibilidad de que Alfonso II fuese el responsable de la destrucción de la lápida de Santa Leocadia es una hipótesis construida sobre otra hipótesis — la atribución de Fita-, pero en el estado actual de la investigación no me parece nada descabellado plantearla, máxime si tenemos en cuenta que, para muchos autores, el origen de la Cámara Santa se sitúa precisamente en su reinado ${ }^{49}$. Incluso en la donación de 812 , cuando el rey Casto evoca a su padre como descendiente directo de Pelayo y lo sitúa "en la más ilustre cima del reino" ("cuius ex filia filius clarior regni apice Froila extitit decoratus"), en el término comparativo me parece todavía entreoír la indignación que al monarca debió producirle la intolerable autoproclamación de su tío como "el más egregio de los príncipes".

A pesar del esfuerzo reivindicativo de Alfonso II, las crónicas asturianas no mencionan la acción constructiva de Fruela en Oviedo. Se trata de una omisión ciertamente intrigante que ha llamado la atención de numerosos estudios ${ }^{50}$. ¿Acaso San Salvador había quedado tan unido a la reconstrucción de su hijo que los cronistas decidieron prescindir de un dato que a todas luces conocían gracias a la inscripción del altar mayor? ¿O sabían en realidad más cosas de lo que allí se cuenta y prefirieron escamotearlas por considerarlas indignas de recuerdo? Más aún: ¿hasta qué puntos debemos fiarnos de las palabras de Alfonso II sobre la actividad arquitectónica de Fruela en Oviedo? ¿Pudo ser la macina de Wímara alguna de las iglesias que el

\footnotetext{
${ }^{49}$ Lo que no significa que el epígrafe se embutise entonces en el macizo del altar de la cripta: una cosa es la damnatio propiamente dicha, que se tradujo en el corte - y probable destrucción - del lado derecho, y otra distinta la reutilización de la pieza sobrante en el podio del altar, que pudo producirse siglos después de estar depositada —o previamente reaprovechada — en algún otro lugar, fuese en la Cámara Santa o en sus proximidades.

${ }^{50}$ Recientemente, lo ha recordado M. J. Suárez Álvarez, "La monarquía asturiana. Nuevas perspectivas de interpretación", en La época de la monarquía..., pp. 203-227 (214). La omisión podría justificarse en la Albendense, que sólo atribuye construcciones o restauraciones a Alfonso II, Ramiro I y Alfonso III, pero no en las dos versiones de la Crónica de Alfonso III, que amplían la nómina a tres monarcas anteriores (Pelayo, Alfonso I y Fávila); cf. J. A. Quirós Castillo y M. Fernández Mier, "Para una historia social de la arquitectura monumental altomedieval asturiana", en L. Caballero, P. Mateos y C. García de Castro (coords.), Asturias entre visigodos y mozárabes (Visigodos y Omeyas, 6), Madrid, 2012, pp. 27-53 (32).
}

rey Casto atribuye a su padre y de la que éste se habría apropiado tras derrotar y asesinar a su hermano? Podríamos seguir arriesgando preguntas de este estilo hasta el mayor de los despropósitos, pero sea cual sea la razón última del silencio, si tomamos por ciertas las afirmaciones de Alfonso II, es posible concluir que la omisión de las crónicas fue voluntaria y, por lo tanto, una obolitio memoriae en toda regla, en la misma medida que la eliminación de la lápida de Wímara y por causas aparentemente interrelacionadas. Los agentes y sus víctimas fueron distintos - los ministros de Alfonso II borraron la memoria constructiva de Wímara, los cronistas de Alfonso III la de Fruela-, pero las dos ocultaciones parecen converger en una misma disputa: la descarnada lucha entre los dos hermanos por el dominio del territorio ovetense, con el apoyo de fundaciones religiosas y un trágico desenlace para ambos. El clima de inestabilidad política que caracterizó la etapa anterior al reinado de Alfonso II, con los continuos enfrentamientos sucesorios en el seno de la familia real y el estamento nobiliario dividido, podría asimismo explicar otras dos extrañas lagunas detectadas en las fuentes del periodo: por un lado, la supresión del reinado de Vermudo I en los Annales Portucalenses veteres, como si detrás de su supuesta abdicación (Crónica de Alfonso III, 20) se escondiese en realidad un destronamiento ${ }^{51}$; y por otro, la exclusión de los tres reyes llamados "usurpadores" en uno de los manuscritos con la lista de los monarcas leoneses — "Post Aurelio Adefonsus castus, qui fundabit Oveto" (Albeldense, XVa; ed. cit., pp. 99 y 172)—, lo que vendría a revelar que "una parte de los territorios norteños no los aceptó como príncipes, no reconoció como propia la corte de Pravia" 52 .

Nuestra tercera inscripción nos traslada de lleno al núcleo de Pravia y a otro lamentable episodio de damnatio memoriae, sólo que enmarcado esta vez en el siglo XVII y por motivos mucho mejor documentados que los medievales. Me refiero a la célebre pieza conocida como "laberinto del rey Silo", una auténtica

\footnotetext{
${ }^{51}$ M. I. Loring García, Cantabria en la Alta Edad Media: organización eclesiástica y relaciones sociales, Madrid, 1987, pp. 183-6.

52 Suárez Álvarez, “La monarquía asturiana...”, p. 220.
} 
sopa de letras de 15 filas y 19 columnas en la que, partiendo del centro y en dirección a los vértices, podía leerse la leyenda Silo princeps fecit un extraordinario número de veces. Como en seguida veremos, la lápida fue hecha pedazos unos años después de que Carvallo la viese "sobre el arco por donde entran del cuerpo de la Iglesia para el cruzero" 53 , lo que podría identificarse con el arco triunfal de acceso al transepto - como sugiere García de Castro ${ }^{54}$ - o con el central de la triple arquería que todavía en 1638 cerraba, a modo de iconostasio, el acceso al crucero desde la nave central, como ha visto Luis Caballero55. En los años treinta del siglo XIX, a raíz de unas obras de restauración del transepto, se recuperó un pequeño pedazo de la lápida original, cuya desaparición ulterior compensaría con creces el arquitecto José Menéndez-Pidal al descubrir en 1975, entre los escombros del presbiterio, un fragmento bastante más completo a partir del cual no ha sido difícil deducir el tamaño de la placa original, que rondaría los $45 \times 53$ x $12 \mathrm{~cm}$. (Figs. 2 y 4). Tradicionalmente, el palíndromo se ha venido atribuyendo con toda naturalidad al rey Silo (774-783) y, en general, ha sido considerado coetáneo de otras dos inscripciones halladas y documentadas en la misma iglesia. Una de ellas ocupó antiguamente el dintel de una ventana altomedieval de dos o tres arcos y, aunque nos ha llegado fragmentada y muy maltrecha, su texto puede reconstruirse gracias a la transcripción que en su día hizo Tirso de Avilés, confirmándonos de paso que se hallaba "sobre una claraboya antigua que está en la dicha iglesia" 56 . Se trata de un epígrafe en honor del titular de la iglesia de Santianes, que seguramente conformaba la ventana axial del ábside prerrománico, a la manera de las tres tituli todavía conservados in situ en la cabecera de San Salvador de Valdedios ${ }^{57}$ :

53 Antigüedades..., p. I49.

${ }_{54}$ Arqueología cristiana..., p. 82.

${ }^{5}$ Las iglesias asturianas de de Pravia y Tuñón. Arqueología de la Arquitectura, Madrid, 2010, pp. 24-5, a partir de la documentación referida más abajo, n. 60.

${ }^{56}$ Antigüedades eclesiásticas y seculares de Asturias, fol. 35v, copia de I845 del ms. del s. XVI del Real Instituto de Estudios Asturianos: Colección: RIDEA, Ubicación: Bib. Fausto Vigil, Signatura: Vigil 8, $\mathrm{N}^{\circ}$ de registro: 473, accesible en <www.bibliotecavirtual.asturias.es $>$ ).

${ }^{57}$ Cf. F. J. Fernández Conde, "La fundación de S. Salvador de Valdediós.

\section{$\dagger$ IN HONORE IO[A]NNIS APOS[TO] LI ET EVA[N] // GE[LISTAE HEAC D] OMUS S(AN)CT[A CO]NSISTI[T]}

"En honor de Juan apóstol y evangelista se levantó esta santa casa”.

Con la tercera inscripción no hemos tenido tanta suerte. Carvallo la vio en 1613 "sobre el arco por donde se entra a la Capilla mayor” — al modo de Cangas y Bańos-, pero no consiguió leerla por hallarse parcialmente cubierta "por un Crucifixo que está sobre el mismo arco, y por averse dado de negro por aquel lado de la pared donde está la piedra" 58 . Y la pieza ha llegado a nuestros días mutilada por partida doble, con buena parte de las dos primeras líneas (y algunos puntos de las siguientes) barridas a golpe de martillo y la mitad izquierda de la piedra cuidadosamente seccionada (Fig. 3). Con todo y con eso, la parte conservada es suficiente para que podamos al menos adivinar que conmemoraba la dedicación de una iglesia (dicata domus) realizada por varios promotores (famuli Dei) - presumiblemente el rey Silo y su mujer Adosinda - con la esperanza de alcanzar la Jerusalén Celeste (ut nos adtollat Sion):

$\begin{array}{ll} & \text { [--]COMPA[---] XPI ECLESIA } \\ & {[--] \text { OLUS GRATIAM ADDAD }} \\ 3 & {[---] \text { EI IUGIS A CRISTO }} \\ & {[---] \text { R NOS DICATA DOMUS }} \\ & {[---] \text { TAMUS FAMULI DEI }} \\ 6 & {[---] U T \text { NOS ADTOLLAT SION }}\end{array}$

Fuentes epigráficas”, en Idem (ed.), La época de Alfonso III y San Salvador de Valdediós. Congreso de Historia Medieval, Oviedo (27 septiembre - 2 octubre) 1993, Oviedo, 1994, pp. 213-247 (227-9).

58 Antigüedades..., p. I49.

${ }^{59}$ Ed. H. Gimeno Pascual y J. del Hoyo, "La epigrafía medieval asturiana. Los epígrafes de la iglesia de San Juan de Santianes de Pravia”, en Asturias entre visigodos..., pp. 13-26 (21-2), donde se corrigen las lecturas anteriores y se acierta a ver que el aparente nexo CT en la palabra dicata (1. 4) revela un intento por parte del lapicida de corregir en $\mathrm{C}$ una $\mathrm{T}$ mal puesta en inicio. El término Sión, desconocido en la epigrafía cristiana hispánica (ib., n. 48), aparece sin embargo sobrentendido en la inscripción que Pablo Diácono escribió para el palatium salernitano de Arechis II en las mismas fechas en que se construía la iglesia de Santianes: regnator tibi summe decus trinomi- 
Sabemos a ciencia cierta que las tres inscripciones fueron desplazadas de su ubicación original a raíz de las radicales reformas que desfiguraron la primitiva iglesia de Santianes durante el segundo tercio del siglo XVII, aunque la razón de que nos hayan llegado tan malheridas no debe achacarse tan sólo a la remodelación del edificio, sino también a las violentas circunstancias en que ésta se produjo $^{60}$. En efecto, durante el verano de 1637, las inscripciones se vieron envueltas en una causa que los vecinos de Pravia - con Diego Menéndez de Miranda al frente- habían puesto contra el cacique local Fernando de Salas por haber derribado (aquel mismo año o poco antes) la antigua capilla mayor de la iglesia con la fatua pretensión de convertirla en poco menos que su panteón familiar. El señor de Salas contaba con el respaldo del obispo de Oviedo - y pariente suyo-Antonio de Valdés, que había defendido la demolición de la capilla "por ser indecente e incapaz de contener el vecindario" y abogaba por la continuación de las obras. Los parroquianos se oponían rotundamente alegando ser "la dicha Iglesia y Capilla mayor fundación real como constaba por la descripción y rótulo antiguo puesto en la tumba y alto de uno de los arcos que están en la dicha Iglesia en el que dice que la hizo y fundó el Príncipe”, en clara referencia al laberinto del rey Silo situado a la entrada crucero $^{61}$. Al final ganó el cacique, y en enero de 1638

nis ille / hebreae gentis Solymis construxit asylum (1. 4-5); cf. C. Lambert, "La produzione epigráfica dei secoli VIII e IX in Salerno e Benevento", en G. Roma (ed.), I Longobardi del Sud, Roma, 2010, pp. 29I-322 (293 y 409).

${ }^{60}$ Sobre dichas reformas, véase la documentación dada a conocer por G. M. de Jovellanos, Colección de Asturias, ed. M. Ballesteros Gaibrois, Madrid, I947-I952, IV, pp. 207-8; F. de Selgas, "La primitiva Basílica de Santianes de Pravia (Oviedo) y su panteón regio", Boletín de la Sociedad Española de Excursiones, X (1902), pp. 5-14 (9), 28-34, y 52-7 (55-7); e I. Cadiñanos Berdeci, "Fondos documentales para la Historia del Arte en Asturias”, Liño, 12 (2006), pp. 7I-88 (82-4). Un análisis completo, en Caballero, Las iglesias asturianas..., pp. 15-6, 29-30 y 46-7.

${ }^{61}$ Real Cédula sobre la Iglesia parroquial de Santianes de Pravia, Madrid, I2 de enero de I638 (Jovellanos, Colección..., p. 207). En el resumen que Seglas hace de los pormenores de este documento, se confunde, por errata, la fecha del embargo (I628 por I638) y, por error, la inscripción fundacional (que él llama "votiva") con el laberinto ("La primitiva Basílica...”, p. 56), confusiones ambas que se reproducen en Caballero, Las iglesias asturianas..., p. I6. En la cédula, es interesante la identificación entre el transepto cerrado por el iconostasio y la "tumba" del monarca. No parece casual que, se alzaba el embargo y se ordenaba la prosecución de las obras, a condición no obstante de que en la nueva "capilla mayor no se diese sepultura, banco, ni otra distinción a la familia de Salas, ni a otra familia o persona alguna", y de que se respetase al pie de la letra el plan de los trabajos a ejecutar, entre los cuales se incluía la eliminación de "los tres arcos pequeños que están en medio de [la iglesia] y se aga uno grande en el medio lugar que sea bien levantado y reçiva la parez que llegue al texado y que a lo más ancho que puedan" ${ }^{2}$. Con todo, el litigio todavía duraba en 1662, fecha de un juicio instructivo en que los de Salas de nuevo "quisieron poner en duda el patronato real de Santianes, y entre otras cosas dando por sentado que ya no existían los rótulos, que el letrero antiguo decía que la Iglesia había el noble pueblo", a lo que Amador de Miranda contestó que "don Fernando de Salas avuelo y parte de los actuales litigantes había desaparecido [entiéndase 'hecho desaparecer'] con cautela y maliciosa disposición la inscripción y las armas reales al tiempo del derribo de la capilla mayor para facilitar sus pretensiones, y se remite a la información de que consta que la piedra decía el Rey Silo me fizo" ${ }^{\text {63 }}$.

Estos datos dejan bien claro que la cifra de Silo no se perdió accidentalmente a consecuencia del derribo del iconostasio, sino que fue despedazada a traición y sobre seguro por el señor de Salas o sus esbirros, probablemente poco tiempo después de la resolución judicial de enero de 1638. Que hiciese lo propio con la lápida fundacional casi podríamos darlo por sentado, en particular si suponemos que también ésta traía el testimonio del

\footnotetext{
en el tramo meridional del transepto, J. Menéndez-Pidal descubriese "dos sepulcros idénticos en su construcción y simétricamente situados con relación a su eje", cuya "ubicación y el cuidado con que están realizados" le llevaron a asociarlos con "personajes de alto rango, justificando el cierre posterior de este tramo del crucero, para convertirle en capilla" ("La basílica de Santianes de Pravia (Oviedo)", en Actas del Simposio para el estudio de los códices del «Comentario al Apocalipsis» de Beato de Liébana (Madrid, 22-25 de noviembre de 1976), I, Madrid, 1980, pp. 279-297, espec. 293).

${ }^{62}$ Cadiñanos, "Fondos documentales...", p. 83.

${ }^{63}$ Pleito sobre las regalías de la Parroquia de Pravia, s. d. (Jovellanos, Colección..., p. 208).
} 
patrocinio regio. En 1637, a los vecinos de Pravia les bastaba la prueba del laberinto para defender la jurisdicción regia de la iglesia, pero tras su desaparición y el incumplimiento por parte de la familia de Salas de las condiciones pactadas sobre las "regalías de sepulcro y banco" en la capilla mayor, lo lógico es que acabasen interesándose asimismo por aquella lápida que Carvallo no había logrado leer. La piedra pudo removerse entonces o hallarse ya en el suelo a raíz de la demolición del ábside prerrománico, pero el caso es que las noticias de finales del siglo XVIII la sitúan fuera de su lugar original y con la mitad del texto ya perdida ${ }^{64}$. Nótese que en el pleito de 1662 se habla de "rótulos" en plural y que los descendientes de Fernando de Salas se defienden declarando "que el letrero antiguo decía que la Iglesia habia el noble pueblo". Mucho me sospecho que dicho "letrero antiguo" no era otra cosa que la propia piedra fundacional, pero deshecha hasta el extremo de permitir a la familia de Salas conjeturar a capricho sobre el texto conservado y desplazar la atención del rey Silo al "noble pueblo". Cualquier espabilado con cuatro latines podría haber reconstruido las desvaídas líneas del arranque con soluciones fingidas del tipo COMPAR[AT] XPI ECLESIA[M] / [POP]OLUS (sic), y traducir: "dispone/conforma el pueblo la iglesia de Cristo" o cualquier cosa por el estilo y al margen de todo lo demás.

En principio, todo lo dicho es compatible con la posibilidad de que la inscripción ya hubiese sufrido la furia de una damnatio memoriae anterior y por causas totalmente ajenas a las aspiraciones de Fernando de Salas. En el fondo, las lesiones de la piedra son dos y nada nos fuerza a considerarlas coetáneas. El señor de Salas pudo perfectamente limitarse a hacer desaparecer la mitad izquierda de una inscrip-

${ }^{64}$ A. J. Banzes y Valdés, "Noticias históricas del Concejo de Pravia (I)", Boletín de la Real Academia de la Historia, 58 (1911), pp. 237-284 (267-8), la vio en 1796 encajada "en la pared de la capilla del Cristo al lado de la Epístola", lamentando "que no está entera, que están gastadas las letras, y aun por las orillas cubierta en parte con el revoco y repellado de cal". ción repicada previamente y a la que, recordemos, se había "dado de negro" ya antes de la visita de Carvallo. Esto es lo que vienen a insinuar Helena Gimeno y Javier del Hoyo en su reciente trabajo sobre el conjunto epigráfico de Santianes, al sugerir que el barrido de las dos primeras líneas pudo ser una estratagema para desvincular la iglesia de Pravia de sus verdaderos promotores —esto es, los que otrora se leían en la piedra- con el objeto de asociar su fundación al rey Silo ${ }^{65}$. Tal era, de hecho, la intención de los vecinos de Pravia y de la familia de Miranda en particular, pero la interpretación de dichos autores no apunta hacia el siglo XVII, sino a un periodo anterior, y se basa en una tesis de mayor calado que constituye en realidad el meollo de su artículo: la posibilidad de que el laberinto de Silo no sea una pieza auténtica, sino un falso, acaso de finales del siglo IX o de tiempos del gran falsario el obispo Pelayo, destinado a probar lo que hasta ahora nos hemos creído todos: que Silo construyó y se enterró en Santianes de Pravia. En el horizonte de esta revisión se halla la reciente datación de la iglesia en torno al año 900 por Luis Caballero y sus colaboradores (supra, n. 55), que ha convertido la inscripción de Pravia en el tercer caso — junto a los de San Juan de Baños y Quintanilla de la Villas- de aparente contradicción cronológica entre los datos que aporta la epigrafía y los resultados que proporciona la arqueología de la arquitectura ${ }^{66}$. Puesto que la discusión está servida y atañe a un asunto complejo y de amplio alcance, merece que le dediquemos la mayor atención.

La principal noticia histórica que permitiría desvincular al rey Silo de la iglesia de Santianes procede del Chronicon rerum memorabilium Hispaniae del flamenco Juan Vaseo. Impreso en Salamanca en 1552, el texto de Vaseo es el primero en el que se menciona y publica la cifra del rey Silo (Fig. 4), pero localizándola ni más ni menos que en el pórtico de

\footnotetext{
65 “La epigrafía medieval asturiana...”, p. 24.

${ }^{66}$ Además de la bibliografía recogida por Gimeno y del Hoyo, "Epigrafía medieval...”, n. 9, véanse las recientes reflexiones de Velázquez, "Epigrafía en la Hispania ...", pp. 310-9 y 327.
} 


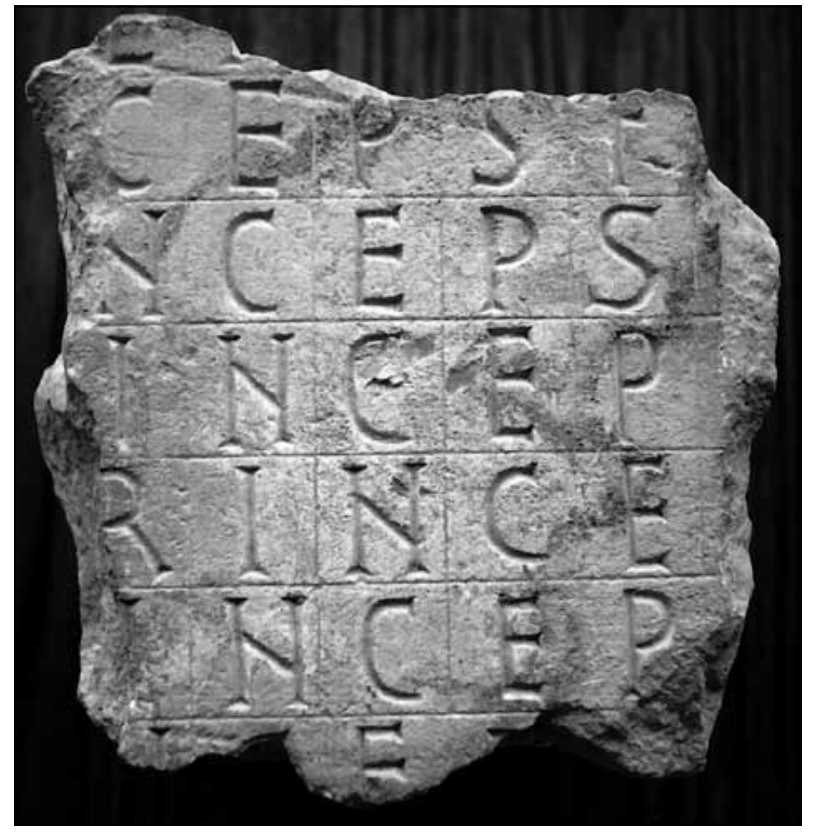

Fig. 2 - Laberinto del rey Silo, fragmento hallado por J. Menéndez-Pidal, Santianes de Pravia.

la iglesia de San Salvador de Oviedo. Muy crítico con algunas de sus fuentes, la inscripción le sirve al humanista para demostrar que la basílica ovetense fue obra del rey Silo y no de Alfonso el Casto, como hasta entonces repetían los cronistas hispanos: "Eodem fere tempore Rex Alfonsus ecclesiam S. Salvatoris Ovetensis civitatis extruendam curavit (...). Ita ferme qui de rebus Hispaniae scripserunt. Sed Silonem esse templi illius autorem constat ex monumento, quod est Oveti in ingressu basilicae Sancti Salvatoris. Ubi legitur ducenties septuagies Silo princeps fecit", a lo que sigue la imagen del laberinto (fols. 121v-122). Por si fuera poco, a continuación añade el siguiente epitafio del monarca: $\mathrm{H} \cdot \mathrm{S} \cdot \mathrm{E} \cdot \mathrm{S}$ · S . S . T . L, abreviatura de $H($ ic) s(itus) e(st) S(ilus). $S$ (it) s(ibi) t(erra) l(evis), claramente un epígrafe romano reinterpretado ${ }^{67}$. Lo sitúa "in mausoleo", se

\footnotetext{
${ }^{67}$ La fórmula sepulcral clásica se construía con el pronombre reflexivo de tercera persona ( $t i b i)$ y no de la segunda ( $s i b i)$, por lo que deduzco que Vaseo —o su fuente — transcribió mal la lápida original (cf. la nota siguiente). Un caso similar y coetáneo lo hallamos en la lectura errónea, en I535, del epitafio
}

entiende que en la propia basílica del Salvador, pues en ella localizaba unos párrafos antes la sepultura del monarca para negar de paso que estuviese en la iglesia de San Juan de Oviedo, como se suponía: "Mortuo Silone, atque Oveti ad divi Ioannis Evangelistae, quam ecclesiam ipse aedificaverat, sepulto (...). Sed Silonem ad D. Salvatoris sepultum esse, non ad D. Ioannis ex monumenti inscriptione patet quod paulo post referemus" (fol. 121).

Pese a la perplejidad que causan estas noticias, Gimeno y del Hoyo les otorgan cierta credibilidad a la luz fundamentalmente de dos argumentos de corte historiográfico (más adelante comentaré los epigráficos y arquitectónicos): 1) según un enigmático "Maestro Custodio" citado a menudo por Carvallo y del que por desgracia no conservamos ninguna obra, el mencionado epitafio —que no el laberinto- del rey Silo se hallaba en el siglo XV — supuesta época de Custodio- en un sepulcro "detrás de la Capilla mayor [de San Juan de Oviedo]”, dato que confirmaría la asociación funeraria de Silo con la capital asturiana, al menos durante la última fase de la Edad Media ${ }^{68}$; y 2) el más antiguo conjunto de fuentes que identifica Santianes como construcción y sepultura del rey Silo — sin mencionar nunca las inscripciones - salió, sin excepción, del siempre sospechoso scriptorium del obispo Pelayo, quien además mostró mucho interés en (re)componer el "mapa funerario" — como lo ha llamado Raquel Alonso- de todos los reyes asturianos cuyos lugares de enterramiento fueron omitidos por los cronistas que lo precedieron ${ }^{69}$. La Albeldense (XV, 6), en efecto, se limita a decir que Silo asentó la

extremeño de Maura (CIL II 720), en el que un tal Juan de Tovar, aficionado a "mirar letras onde quiera que las ve escritas", leyó en el cuarto renglón s(epulta) s(unt) s(it) s(ibi) t(erra) l(evis), cuando pone s(ita) e(st) s(it) t(ibi) t(erra) l(evis); cf. E. Cerrillo Martín de Cáceres, Claudio Constanzo y la epigrafía extremeña del siglo XIX, Madrid, 2007, p. 14.

${ }^{68}$ Carvallo, Antigüedades..., p. 156, que también transcribe la antepenúltima letra como una $S$ en lugar de la $T$ preceptiva, aunque ignoro si copiando de Custodio o de Vaseo, puesto que los cita a ambos en la misma frase. El flamenco no parece haber conocido la obra del asturiano, dado que no aparece citado entre sus fuentes, presentadas al inicio del Chronicon, fols. 7-9v.

69 "Patria vallata asperitate moncium. Pelayo de Oviedo, el archa de las reliquias y la creación de una topografía regia”, Locus Amoenus, 9 (20072008), pp. 7-18 (17). 


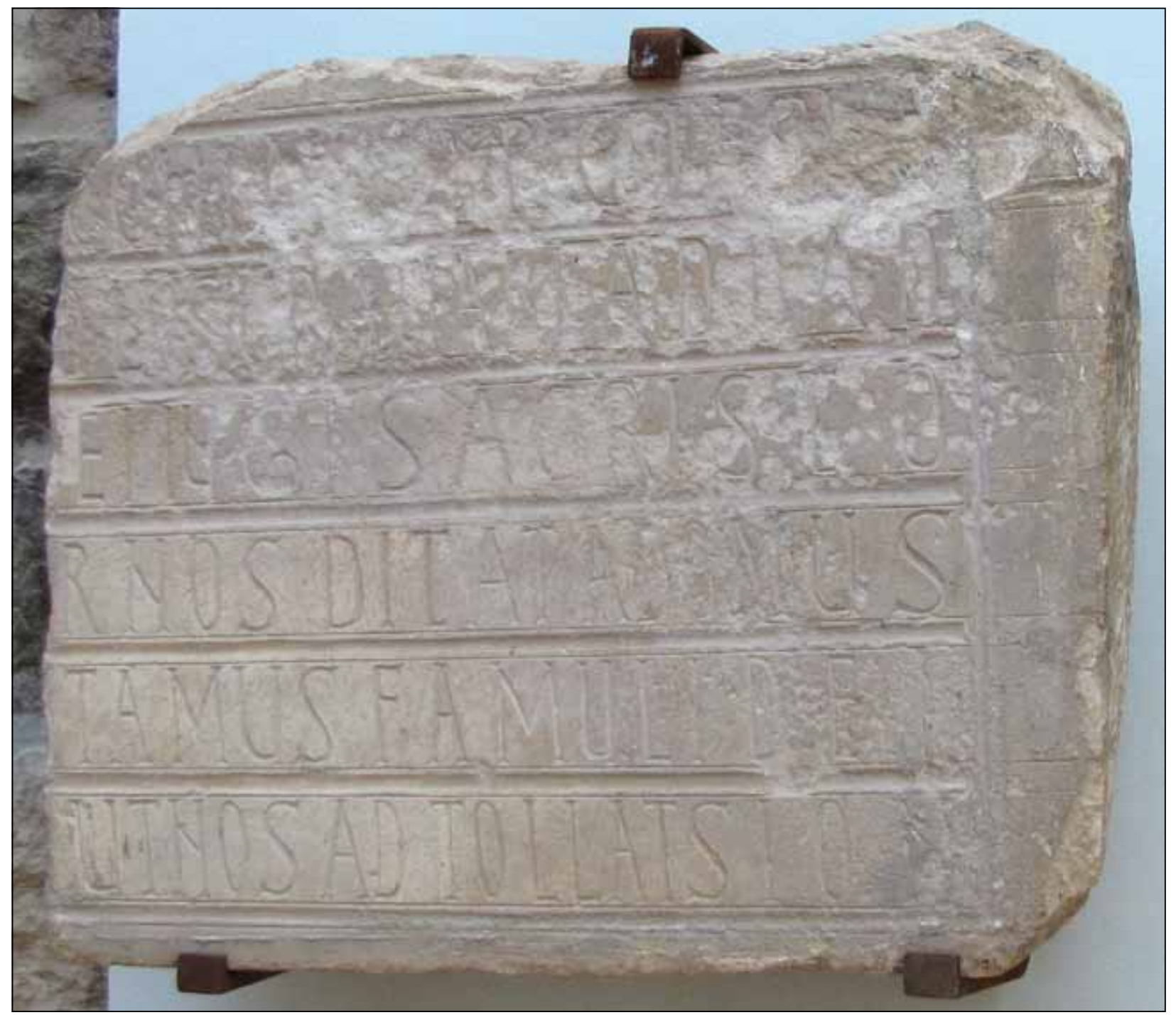

Fig. 3 - Inscripción fundacional de Santianes de Pravia.

corte en Pravia ("in Prabia solium firmavit"), y las dos versiones de la Crónica de Alfonso III ni siquiera eso. Las primeras noticias las encontramos en la conocida interpolación pelagiana de la Crónica de Sebastián en que se relata la traslación a Pravia de las reliquias de Santa Eulalia de Mérida ${ }^{70}$ y en una falsa donación del "monasterio" de Santianes a la sede

\footnotetext{
${ }^{70}$ Cf. F. Prelog, Die Chronik Alfons'III, Fráncfort, 1980, pp. 88-9.
}

ovetense por Alfonso III y dońa Jimena en $905^{71}$. Está claro que entre Custodio y Vaseo existió una tradición historiográfica que situaba en Oviedo tanto el laberinto como el fabuloso epitafio del rey Silo, pero debo decir que a mí me parece excesivamente desamparada y quebradiza para descartar de un plumazo el enterramiento del monarca en Santianes. Se trata, ciertamente, de la "tradición más

${ }^{71}$ Liber Testamentorum, fol. $20 v$ (ed. cit., p. 496). 


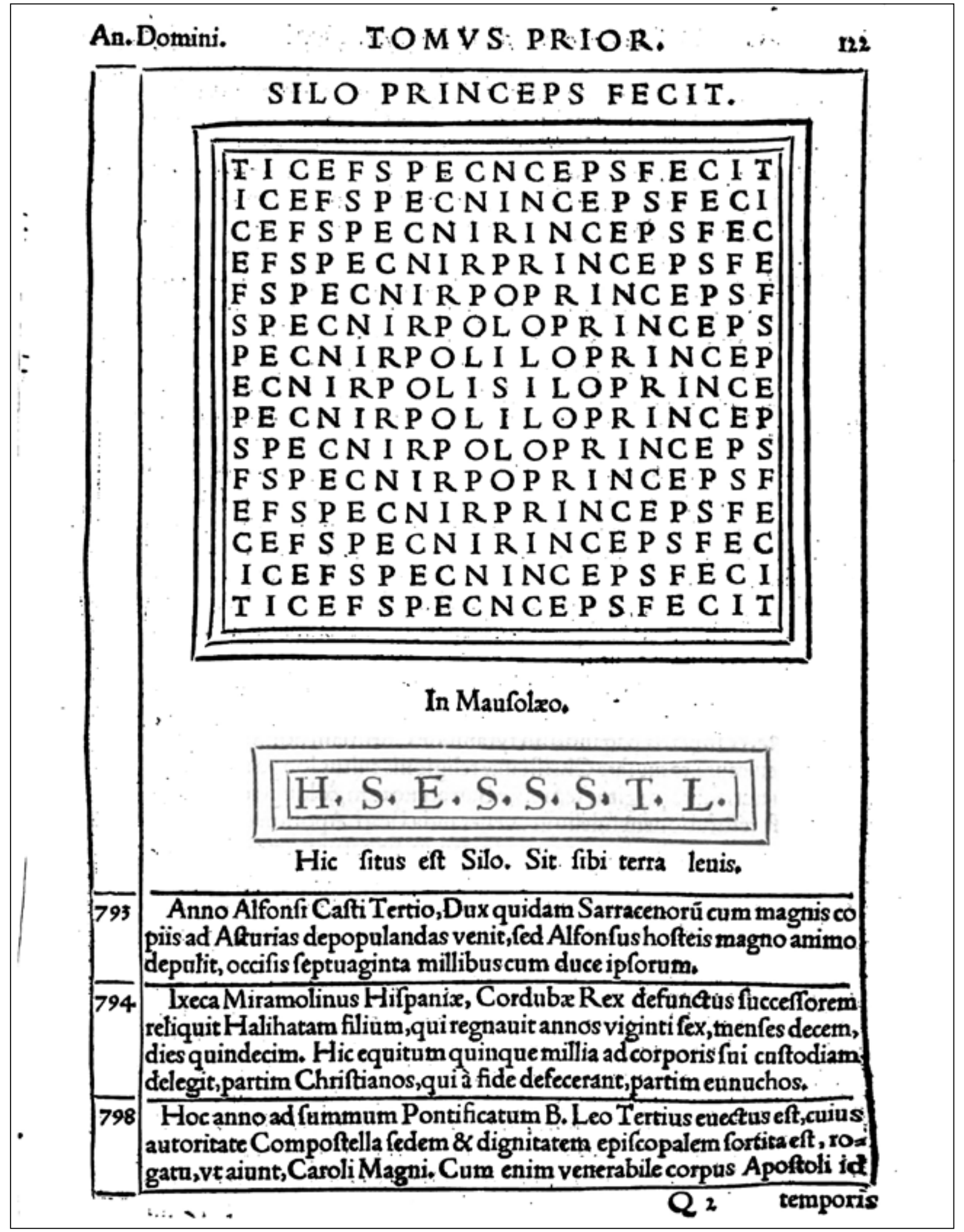

Fig. 4 - Laberinto del rey Silo, según J. Vaseo, Chronicon rerum memorabilium Hispaniae, Salamanca, 1552, fol. 122. 
antigua" en que se alude a las inscripciones ${ }^{72}$, pero su testimonio no deja por ello de ser muy tardío, y el de Vaseo en particular está plagado de incoherencias y contradicciones difíciles de aceptar. Prestemos atención a las más evidentes. En primer lugar, si tenemos en cuenta que el Maestro Custodio era aficionado a copiar las inscripciones de su tierra, se me hace en verdad extraño que no mencionase la piedra del Salvador con el laberinto ${ }^{73}$. De hecho, aunque Carvallo acepta que el supuesto epitafio del monarca podía estar (o haber estado) en San Juan de Oviedo, lo hace sin haberlo visto personalmente - “y Custodio dize que vio una piedra detrás de la Capilla mayor"- y sin realmente ocultar la contrariedad que dicha noticia le suscita no sólo a la luz de la documentación pelagiana, sino al comprobar la exacta ubicación del laberinto en Santianes de Pravia, justo "sobre el arco por donde entran del cuerpo de la Iglesia para el cruzero". Para resolver tal dilema, y pese a confesar no haber hallado en aquella iglesia "sepultura, rastro, o señal de sepultura que pareciesse aver sido de estos Reyes", al clérigo asturiano no se le ocurre mejor cosa que plantear un más que inverosímil traslado de los cuerpos de Silo y Adosinda de la iglesia de Pravia al monasterio de Oviedo, en consonancia con el de la reliquias de la mártir emeritense en tiempos de Alfonso el Casto: " $y$ pienso fueron llevados a Oviedo sus cuerpos, como lo fue el de la señora Santa Eulalia (...), porque ay tradición en este Convento, que están allí, y enseñan la sepultura de Don Silo"74. En segundo lugar, es sumamente revelador que Vaseo no sólo no coincida con Custodio en la localización del epitafio - atreviéndose incluso a contradecir la tradición que lo ubicaba en la iglesia de San Juan—, sino que

\footnotetext{
${ }^{72}$ Gimeno y del Hoyo, "La epigrafía medieval...", p. I8.

${ }^{73}$ La cantidad de epígrafes - la mayoría epitafios, a decir verdad-que Carvallo toma de Custodio es extraordinaria (Antigüedades..., pp. 156, 255, 292, 295, 317, 347, 358, 368, 386...). El más antiguo que he encontrado está fechado en la "era de I400" (ib., p. 386), lo que nos da un post quem para datar la misteriosa obra de Custodio. Por su apego a la epigrafía, yo lo situaría más cerca del siglo XVI que del XIV, a diferencia de C. Cid Priego, "Las joyas Prerrománicas de la Cámara Santa de la Catedral de Oviedo en la Cultura Medieval (Continuación)", Liño, Io (1991), pp. 7-46 (13).

${ }^{74}$ Antigüedades..., p. 156.
}

confunda con el Evangelista (Oveti ad divi Ioannis Evangelistae) al más antiguo titular del monasterio de San Juan y San Pelayo de Oviedo, que nunca fue otro que el Bautista. El lapsus es garrafal y se me antoja el indicio más claro de que Vaseo no sólo no había visto las dos inscripciones de las que habla, sino que nunca llegó a visitar Oviedo. De hecho, su osada atribución de la basílica del Salvador al rey Silo en detrimento de Alfonso el Casto constituye — si se me permite decirlo así- un auténtico disparate, hasta el punto de que Carvallo prefiere obviarla y limitarse a leer la parte del párrafo en cuestión que casaba con Custodio: "Y Baseo dize, que está este Rey en el Monasterio de San Iuan de Oviedo". Por último, la posibilidad de que Silo hubiese sido enterrado alguna vez in ingressu basilicae Sancti Salvatoris es poco menos que imposible, puesto que tenemos perfecta constancia de que el espacio destinado desde Alfonso II a acoger los cuerpos de los reyes asturianos fue el pórtico occidental de la iglesia de Santa María, vecina de San Salvador por el norte, mientras que entre Pelayo y Vermudo I los monarcas recibieron sepultura en iglesias radicadas en los territorios de su dominio o propiedad, en línea con las costumbres funerarias de los reyes visi$\operatorname{godos}^{75}$. Tal era la práctica más natural en tiempos del rey Silo, razón por la cual Raquel Alonso no ve ningún inconveniente en transigir en este punto con el obispo Pelayo. Me pregunto si el lapsus que mencionaba antes no le vendría a Vaseo de confundir Oviedo con Pravia, pues el titular de Santianes sí que fue siempre Juan el Evangelista.

Tengo la impresión, en definitiva, de que Vaseo se equivocaba de parte a parte. Ya Ambrosio de Morales lo vio claro cuando llegó a Asturias tan sólo veinte años después de la publicación del Chronicon y se quedó estupefacto al comprobar que el laberinto se hallaba en Pravia y no en la capital asturiana: "A Vaseo le engańaron — comenta, a sabiendas de que

${ }^{75}$ Cf. R. Alonso Álvarez, "El Panteón de los reyes de Asturias: modelos ideológicos", en Modelos, intercambios y recepción artística (de las rutas marítimas a la navegación en red), Palma de Mallorca, 2008, I, pp. 37-47 (45-7). 
el cronista no conocía Oviedo de primera manoen decirle que esta Piedra estaba en Oviedo y que el Rey Silo estaba allí enterrado" "76. Me cuesta creer que el humanista sacase la noticia de una crónica u otra fuente similar. Más bien le pasarían una hoja suelta con la figura de las inscripciones, acompañada de una breve nota con la información equivocada o mal interpretada por el propio Vaseo. O incluso sin ella, pues nadie nos dice que la cifra no circulase ya entonces al margen de la historia, en forma de pasatiempo erudito o de ejercicio escolar, como en un manuscrito portugués del siglo XVIII en que aparece enlazada al epitafio a manera de acertijo, vacía de contexto y solución, encabezada tan sólo con el siguiente título: "Letreiro que se lè por muitas maneras" (Fig. 5) 77 . La vinculación del laberinto con la basílica del Salvador parece una confusión tardía nacida en torno a las noticia pelagiana de la traslación a Oviedo de las reliquias de la mártir emeritense, como sospechaba Carvallo, o de la espuria donación de Santianes a la sede ovetense el año 905 (supra, n. 71). A ello también debió contribuir la ilusa identificación del epitafio de Silo con la lápida romana de San Pelayo. La ubicación del convento al norte de la iglesia funeraria de Santa María y el servicio litúrgico que ahí prestaban las monjas en memoria de los monarcas fallecidos generaban una

\footnotetext{
${ }^{76}$ Viaje..., p. IIo. El valor del testimonio de Morales es todavía mayor si consideramos que en I57I, sólo un año antes de emprender su célebre viaje, estaba convencido de que la piedra con la cifra se hallaba en Oviedo y formaba parte del epitafio del rey Silo, tal como puede comprobarse en su descripción del Códice Albeldense de El Escorial con el conocido laberinto de Vigila (cf. Gimeno y del Hoyo, "La epigrafía medieval...", p. 27). Parecida fue la apreciación de Tirso de Avilés tras ver la inscripción de Silo "en lo alto de la dicha Iglesia [de Pravia]" unos quince años después de Morales: "y ansí están erradas las crónicas que dicen que está sepultado en la Iglesia de San Juan de Oviedo" (Antigüedades..., fol. I6v).

${ }^{77}$ Biblioteca General de la Universidad de Coimbra, ms. 338, fol. 477v, de autor desconocido (Catálogo de manuscritos. Códices 251 a 555, Coimbra, 1945, pp. 59-66). Publica el dibujo D. Higgins, Pattern Poetry. Guide to un Unknown Literature, Nueva York, 1987, pp. 29, 203 у 205, fig. 5.8. Es evidente que la ilustración se inspira en la lámina de Vaseo, sea directamente $\mathrm{o}$ a través de alguna de las reproducciones que aparecieron en otras crónicas posteriores (cf., por ejemplo, J. del Castillo, Historia de los reyes Godos, Madrid, 1624, pp. 141-2, y G. González Dávila, Teatro Eclesiástico de las Iglesias metropolitanos y Catedrales de los Rcinos de las dos Castillas, III, Madrid, 1645, pp. 112-3), pero es un bonito y desconocido ejemplo de la transmisión del laberinto en un contexto distinto del cronístico, puramente literario.
}

atmósfera de lo más evocadora para echar a volar la imaginación ${ }^{78}$. Todavía a finales del siglo XVI, la comunidad creía ciegamente que el fundador de su monasterio había sido el rey Silo y que allí seguía enterrado: en una tumba "en el suelo - le comentaban las monjas a don Tirso- arrimada a la pared que corresponde con San Vicente"; sólo que "no tiene título su sepultura", cavilaba él ${ }^{79}$.

Es posible que me equivoque, pero el testimonio de Vaseo me parece tan tardío, solitario e indirecto, que no veo ninguna razón para darle mayor crédito que al "mapa funerario" del obispo Pelayo y, menos aún, que a la lógica sepulcral de los reyes astures - y visigodos - anteriores a la fundación de Santa María del Rey Casto. Además, tampoco entiendo por qué nadie había de falsificar una inscripción destinada a Santianes para luego colocarla en la catedral de Oviedo, a no ser que imaginemos un doble traslado, de Pravia a Oviedo antes de Vaseo y de Oviedo a Pravia entre 1552 y 1572, cosa difícil de justificar y que, en cualquier caso, tampoco negaría que el destino original del laberinto fuese la iglesia de Santianes. Por desgracia, los datos estrictamente epigráficos ayudan poco a resolver el dilema, como ya se ha comprobado en el reciente debate sobre la epigrafía de San Juan de Baños y Quintanilla de la Viñas. Ninguno de los tres tituli conservados en Santianes tiene un rasgo paleográfico verdaderamente distintivo que encaje mejor en el siglo VIII que en el siglo X (o viceversa). La concentración de laberintos en la miniatura hispana de la décima centuria, con los dos ex libris de Alfonso III (866-910) en sendos códices escurialenses como cabeza de serie (P.I.7 y T.II.25) y sin más precedentes conocidos

\footnotetext{
${ }^{78}$ Cf. F. J. Fernández Conde, "Orígenes del monasterio de San Pelayo", en Semana de historia del monacato cántabro-astur-leonés. XV Centenario del nacimiento de San Benito, Oviedo, 1982, p. 99-121 (103-110), y E. Carrero Santamaría, "La ciudad santa de Oviedo. Un conjunto de iglesias para la memoria del rey", Hortus Artium Medievalium, I3 (2007), pp. 275289",pp. 375-389 (384).

${ }^{79}$ Antigüedades..., fol. 35v. El lugar coincide con el área donde Custodio vio la lápida romana, "detrás de la Capilla mayor" del monasterio, en la medida en que dicha zona limitaba a mediodía con las dependencias septentrionales del claustro de San Vicente.
} 


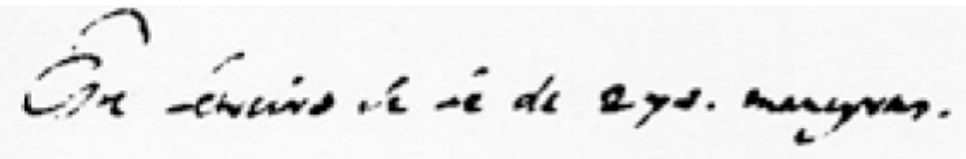

TI CEFS PECNCEPSFECIT I $-E F S P E C N I N C E P S F E C I$ CEFSPECNIRINCEPSFEC EFSPECNIRTRINCEPSTE ES PECNIRPOPRINCEPS F SPECNIRPOLOPRINCEPS PECNIRIOLILOP I INCEI ECNIRPOLISILOPRINCE PECNIRPOLILOPRINCEP SPECNIRPOLOPRINCEFS ESPECNIRPOPRINCEPSE EFSPECNSRPRINCEPSFE CEFSFECNIRINCEPSFEC ICEFSFECNINCEPSEECI TICEFSPECNCEDSFBCIT

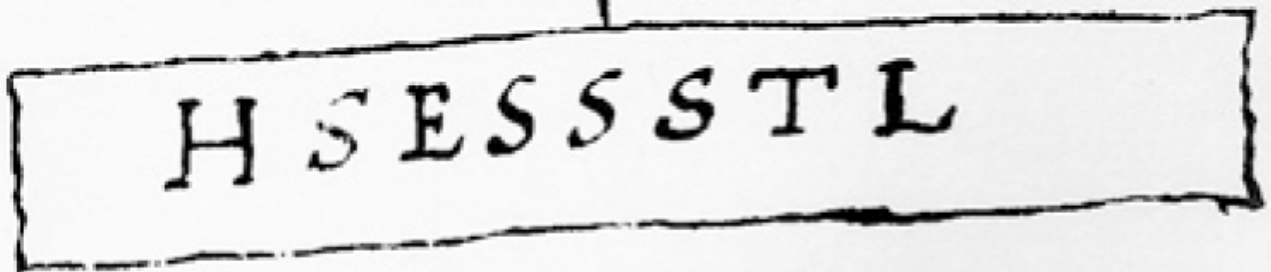

Fig. 5 - Biblioteca General de la Universidad de Coimbra, ms. 338, fol. 477v. 
que la cifra del rey Silo ${ }^{80}$, es un dato ciertamente interesante, en la medida en que entre la piedra y los manuscritos se extiende un inquietante vacío de prácticamente un siglo, pero me parece irrelevante a efectos de datación mientras no esté respaldado por otros indicios significativos que apunten en la misma dirección. A nadie escapa, por lo demás, que en los inestables y mutilados siglos de la primavera medieval los casos 'aislados' y las intermitencias son tanto o más frecuentes que los casos 'acompañados' y las continuidades. La época que discutimos está llena de amplias lagunas que no es difícil rellenar imaginando 'eslabones perdidos'. Para el caso que nos ocupa, bastará recordar, con García de Castro ${ }^{81}$, el clásico interrogante sobre la posible existencia de una miniatura asturiana que haría más 'coherente' la datación temprana de la pieza de Pravia con los primeros testimonios conocidos de la tradición manuscrita, dentro, no obstante, de una lógica interpretativa en la que la posibilidad histórica de que algo haya podido ocurrir se supedita en exceso al ansia de hallar nexos de unión o de transición, relaciones de causa-efecto, derivaciones o influencias más o menos directas y otras formas de coherencia que se me antojan absolutamente artificiales, por cuanto tienden a olvidar, parafraseando a Nassim Taleb, que lo que no sabemos fue muchas veces más importante que lo que sabemos.

Me permito esta última reflexión muy a propósito del tercer y, al fin y al cabo, principal argumento que ha llevado a Helena Gimeno y Javier del Hoyo a ensayar su difícil revisión de las inscripciones de Santianes: en palabras de los propios autores, "el reciente análisis arqueológico de la arquitectura de la iglesia", dirigido por Luis Caballero y que "ha dado como resultado que la construcción de la misma es del siglo X"82. No hay duda de que el minucioso

\footnotetext{
${ }^{80}$ J. Domínguez Bordona, "Ex-libris mozárabes", Archivo Español de Arte y Arqueologia, XI (1935), pp. 153-163.

${ }^{81}$ Arqueología cristiana..., p. 83.

82 "Epigrafía medieval...", p. I5. La monografía de Caballero, Las iglesias asturianas..., debe completarse con el trabajo del mismo autor "Observaciones arqueológicas sobre producción arquitectónica y decorativa de las iglesias de S. Miguel de Lillo y Santianes de Pravia", Asturias entre visi-
}

trabajo de Caballero es el estudio más completo y riguroso que se ha hecho nunca de la iglesia de Pravia, pero no por ello está exento de apreciaciones y conclusiones discutibles, máxime si lo leemos al trasluz del polémico modelo "mozarabista o rupturista" que el arqueólogo ha venido defendiendo durante los últimos dos decenios y con el que ha hecho añicos la imagen - tan fosilizada, ciertamente- que hasta ahora se tenía de la arquitectura de época visigoda ${ }^{83}$. A mi entender, la aportación más importante - o indiscutible — de su trabajo no es la reconsideración cronológica de Santianes, sino la exacta delimitación de todos los elementos arquitectónicos originarios de una fábrica que ha llegado al siglo XXI radicalmente transformada a raíz de las reformas del XVII y el XIX y de la lamentable restauración de los años setenta del siglo XX. Por un lado, se ha constatado que de la iglesia primi-

godos..., pp. 89-124.

${ }^{83}$ Frente al "modelo visigotista o continuista", Caballero pospone al siglo IX la mayoría de las iglesias abovedadas y de sillería que hasta ahora se suponían paradigmáticas del siglo VII (de San Pedro de la Nave a Quintanilla de las Viñas, pasando por Bande, Bańos, Montelios, etc.), basándose, sustancialmente, en su supuesta filiación con el arte de los "castillos del desierto" sirio-palestino, cuyas fórmulas arquitectónicas y decorativas llegarían sistemáticamente a la Península Ibérica de la mano de la dinastía omeya a partir de mediados del siglo VIII. En este esquema, las iglesias tradicionalmente consideradas visigodas pasan a convertirse en variantes de la arquitectura mozárabe, y el siglo VII se interpreta como un periodo de regresión en materia constructiva que no fue capaz de producir más que iglesias de planta basilical y armadura de madera. Se resumen los principales detalles y argumentos del modelo, en L. Caballero, "Un canal de transmisión de lo clásico en la Alta Edad Media española. Arquitectura y escultura de influjo omeya en la Península Ibérica entre mediados del siglo VIII e inicios del siglo X", $A l$ Qantara, XV (1994), pp. 231-348, y XVI (1995), pp. 107-124; "La arquitectura denominada visigoda, ¿es realmente tardorromana o prerrománica?”, en Visigodos y Omeyas. Un debate entre la Antigü̈edad tardía y la alta Edad Media (Mérida, 1999), Madrid, 2000, pp. 207-248; y "Acerca del paisaje arquitectónico hispánico inmediato al año 711 (entre Toledo y el territorio astur y vasco)", en E. Baquedano (ed.), 711: Arqueología e Historia entre dos mundos, Alcalá de Henares, 2011, pp. 257-274. Entre las voces divergentes, cf. A. Arbeiter, "Alegato por la riqueza del inventario monumental hispanovisigodo", en Visigodos y Omeyas..., pp., 249-263; R. Collins, La España visigoda, 409-711, Madrid, 2005, pp. 195-205; G. Ripoll y E. Carrero, "Art wisigoth en Hispania: enquête d'une révision nécessaire", Perspective. Revue de l'Institut National d'Histoire de l'Art, 2009/2, pp. 256-276 (266-7); G. Ripoll et al., "La arquitectura religiosa hispánica del siglo IV al X y el proyecto del Corpus Architecturae Religiosae Europeae-CARE-Hispania", Hortus Artium Medievalium, 18 (2012), pp. 45-73; A. Uscatescu y J. C. Ruiz Souza, “'Orientalismos' y 'entanglement' cultural: estímulos y desenfoques historiográficos”, Anales de Historia del Arte, 22/II (2012), pp. 297-308; e Idem, "El "occidentalismo" de Hispania y la koiné artística mediterránea (siglos VII-VIII)", Goya, 347 (20I4), pp. 95-II5. 


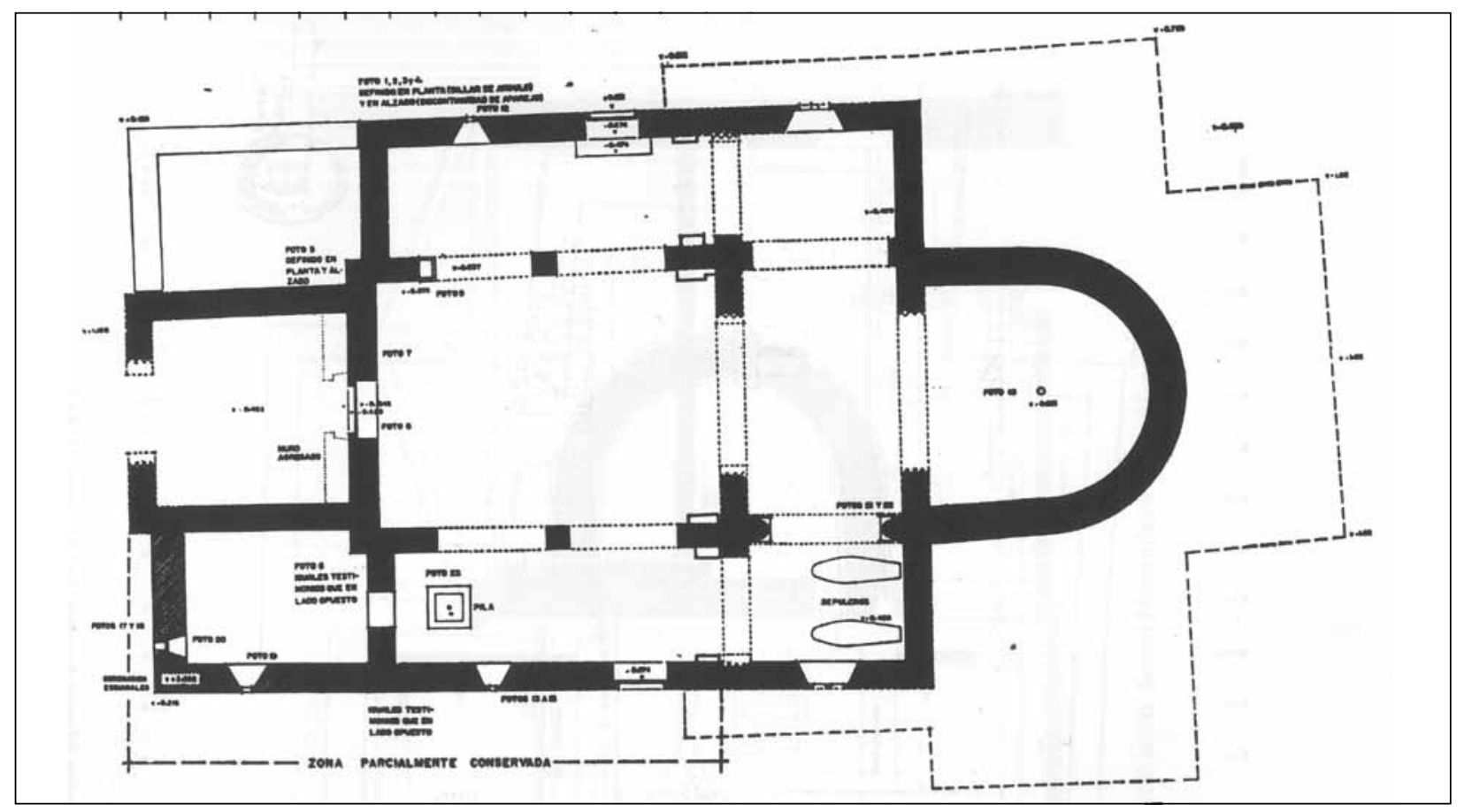

Fig. 6 - Santianes de Pravia, planta de la iglesia originaria según J. Menéndez-Pidal, I980.

tiva (Fig. 6) apenas ha sobrevivido otra cosa que el arranque de sus muros perimetrales, de forma que lo único que podemos asegurar a ciencia cierta es que el primer Santianes era un santuario de planta casi cuadrada, con un único ábside en forma de semicírculo peraltado en su interior, aula de tres naves y transepto, piscina bautismal en el extremo occidental del colateral sur y pequeño pórtico sin función funeraria abierto a la nave central. Algunos indicios permiten sospechar que el ábside también era curvo en el exterior y estaba cubierto con bóveda de toba, pero se nos escapa enteramente la morfología y número de las arquerías que dividían las naves, su forma de conexión con el transepto, y la cubierta y organización interna de éste último. Por otro lado, el hecho de que no se haya encontrado ni una sola huella de la existencia de una construcción previa permite también asegurar que el edificio descrito fue, en efecto, el Santianes más antiguo, mientras que por los restos de los muros conservados correspondientes a la denominada Etapa II (reformas medievales) parece asimismo bastante probable que dicha iglesia no sufrió ninguna reforma estructural importante en época altomedieval. Todo esto nos obliga a asignar la arquitectura del edificio original a un único momento histórico.

Hasta aquí lo irrefutable. La discusión empieza cuando nos planteamos si los datos arquitectónicos que acabo de exponer son suficientes y suficientemente representativos para arriesgar una cronología. Yo, la verdad, no lo creo. Como es obvio, Caballero opina lo contrario, pero para demostrarlo tiene que acudir al único método a nuestro alcance cuando ninguno de los restos arqueológicos conservados está asociado a materiales bien datados (tejas, enlucidos, etc.) o con una fecha inequívoca (como monedas o inscripciones). Es decir, a la comparación formal y tipológica con otros edificios mejor o peor conservados, línea de estudio tan legítima como cualquier otra variante de la historia del arte, pero de escasa utilidad cronológica cuando se aplica a monumentos tan solitarios y mal conocidos como 
el de Pravia. Sobre todo porque las semejanzas que se consiguen detectar, con frecuencia no se refieren sino a partes sueltas del edificio (a las que además se les acaban presuponiendo elementos no verificados), predeterminando la justificación de las piezas desgajadas. Por ejemplo, la asimilación del transepto de Santianes "al grupo mozárabe de iglesias de crucero tripartito cubierto con madera de Utrero (2006: 127-130), Bobastro, Laurosa y Escalada y Nazaré", no sólo desecha de un plumazo que el de Pravia fuese corrido o estuviese abovedado, sino que obliga a tratar de explicar su extraña vinculación con un ábside semicircular en el interior (y seguramente también en el exterior) planteando una segunda conjetura mejor o peor hallada, pero sospechosamente orientada a confirmar la hipótesis de partida; así, que "podríamos estar ante un primer intento de solucionar el abovedamiento de la planta circular", cosa que hasta cierto punto permitiría poner en relación el santuario de Pravia "con los ábsides circulares mozárabes, a pesar de que sean rectos en el exterior" ${ }^{84}$. Se desestiman en cambio sus similitudes con algunos ábsides hispanos tardorromanos y, en particular, con el vecino de Veranes (Gijón), cuando el hecho mismo de que el de Santianes sea una rara avis sin 'sucesores' en la arquitectura asturiana vendría más bien a indicar que estamos ante el último ejemplar de una opción arquitectónica definitivamente descartada a partir — se supone- de Alfonso II y con la que a lo mejor se había venido experimentando en los edificios restaurados o de nueva planta — todos perdidos- que las fuentes atribuyen a los monarcas anteriores a Silo ${ }^{85}$. Francamente, a mí me parece que una planta tan sencilla y sin alzado como la de Santianes tiene las mismas posibilidades de haber sido concebida en el siglo VIII como en el siglo X. La información arquitectónica de que

\footnotetext{
${ }^{84}$ Las iglesias asturianas..., p. 52-4, y "Observaciones arqueológicas...", p. III. La cita bibliográfica es a M. Á. Utrero Agudo, Iglesias tardoantiguas y altomedievales en la Península Ibérica: Análisis arqueológico y sistemas de abovedamiento (Anejos de AEA, LXIII), Madrid, 2006.

${ }^{85}$ Cf., en esta línea, V. Nieto Alcaide, Arte Prerrománico Asturiano, Salina, 1989, pp. 28-33.
}

disponemos es demasiado escasa para ensayar una filiación tipológica precisa tanto con lo visigodo o tardoantiguo como con lo mozárabe, justificada en última instancia por la manifiesta desviación que la planta presenta respecto a la arquitectura asturiana (conocida) del siglo IX y, por lo tanto, igual de chocante al inicio que al final del periodo. El peso de balanza habrá que buscarlo, por consiguiente, en otro tipo de indicios.

Descartados los epigráficos, sólo nos quedan los decorativos, que en el fondo constituyen un pilar fundamental de la propuesta cronológica de Caballero, pero en cuyo análisis volvemos a toparnos con el mismo problema que antes: las limitaciones de la comparación tipológica y formal. La escultura en relieve de Santianes se reduce a ocho piezas pertenecientes todas a los canceles que cerraban el ábside prerrománico, documentados en las reformas del siglo XVII ${ }^{86}$, y exhibe una pequeña colección de motivos ornamentales (corazones, roleos vegetales de traza geométrica, zarcillos enrollados, "hojas inclusas", círculos secantes y tangentes, etc.) para los que se han señalado paralelos (o parecidos) tardorromanos, visigodos, bizantinos, omeyas, asturianos y mozárabes (Fig. 7) ${ }^{87}$. Caballero ve "prototipos" a su entender medulares en Jirbat al-Mafyar (Palestina), llegando incluso a trazar el mapa y la secuencia de su transmisión a la Península como sigue: entrada por Villajoyosa (Alicante) en la segunda mitad del siglo VIII, influencia en el Norte a través de Lillo a mediados del IX, llegada a Pravia, Braga y Oviedo hacia el ańo 900 y expansión a Lena y otros talleres derivados poco después ${ }^{88}$. Puedo asumir que en todos estos conjuntos se percibe un mismo caudal de motivos y combinaciones de motivos, e incluso que sus analogías lexicales y sintácticas son mayo-

\footnotetext{
86 "Ytem que se quiten las dos piedras labradas que están arrimadas a los pilares del arco de la capilla mayor" (Cadiñanos, "Fondos documental...", p. 83).

87 Para la descripción de las piezas, las comparaciones formales y toda la bibliografía anterior, cf. Caballero, Las iglesias asturianas..., pp. 47-50 y 57-60, y "Observaciones ...", p. II3.

${ }^{88}$ Exposición muy clara en "Observaciones ...”, pp. II8-9, y "El paisaje...", p. 268.
} 
res que las que se puedan observar entre cualquiera de ellos y otras obras afines, visigodas y bizantinas, señaladas por otros autores. Lo que me cuesta mucho de aceptar es que esta coherencia puramente ornamental —en la que apenas caben consideraciones estilísticas en sentido estricto- de un número de obras (o fragmentos de obras) muy restringido, pero que se extiende a lo largo de más de tres siglos, pueda realmente traducirse en un estema o árbol de 'vinculaciones' o relaciones de 'parentesco', que es lo que denotan términos como 'canal', 'transmisión', 'derivación', 'dependencia' o 'influencia'. Si en periodos artísticos mejor conocidos como el románico, donde el material escultórico con el que se trabaja es mucho mayor (casi big data por contraste con el prerrománico) y en la mayoría de los casos no ha perdido su marco arquitectónico original, los especialistas siguen discrepando en cuanto a la prioridad de unos monumentos sobre otros dentro de una misma 'familia' artística o en torno a sus grados de conexión o parentesco, ¿qué podemos esperar de un patrimonio artístico tan mermado, disperso y descontextualizado como el altomedieval, que además es sustancialmente ornamental y en gran medida inercial (o humilis)? Con la desventaja añadida de que, como han recordado Alexandra Uscatescu y Juan Carlos Ruiz Souza a propósito, justamente, del "canal de transmisión omeya", el repertorio decorativo del que estamos hablando hunde sus raíces en el sistema ornamental romano y tardorromano, ese organismo vivo, "conservador y proteico a la vez (...), con siglos a sus espaldas de intercambios" mediterráneos, que hace que la presencia de motivos decorativos semejantes a una y otra orilla del Mare Nostrum pueda ser, en efecto, "multicasual" y un fenómeno "muy esquivo a la hora de datar" 99

En la dinámica artística del periodo tuvieron igual cabida los canales de transmisión -léase, difusión, influencia, etc. - que los procesos de desarrollo independiente (en la sincronía o en la diacronía) de productos parecidos a partir de un

\footnotetext{
89 “El «occidentalismo»...”, pp. Iо9-Iı, y “'Orientalismos'...”, pp. 306-8.
}

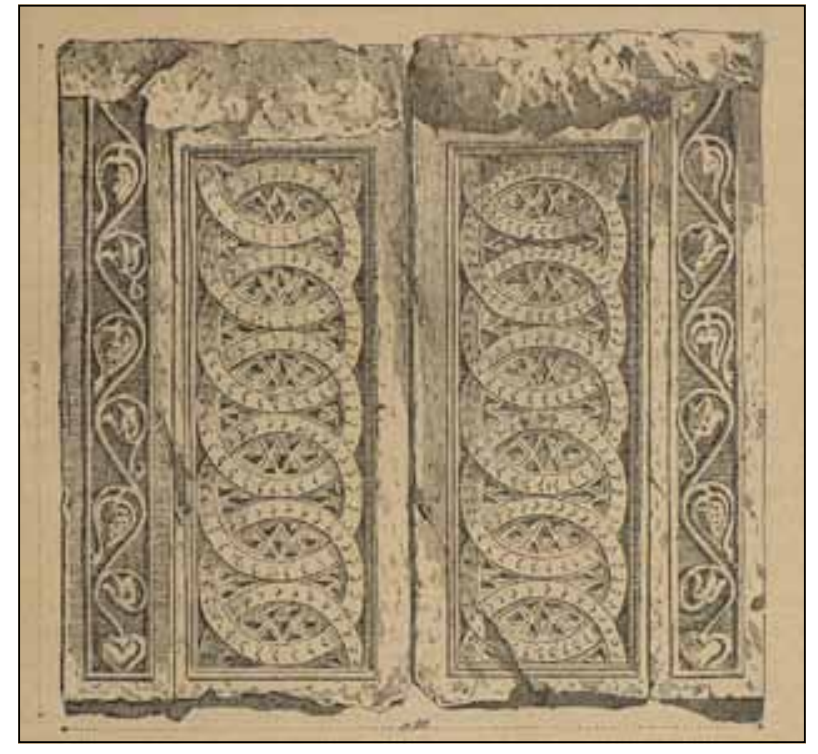

Fig. 7 - Placas de cancel de Santianes de Pravia, según Selgas, I902.

sustrato común. La clave de la cuestión no está en elegir entre una u otra dinámica como patrón explicativo, sino en tener en cuenta las dos y tratar de dilucidar cuál podría ser la más válida o razonable para esclarecer cada caso en particular. El mayor inconveniente del diagrama relacional trazado por Caballero es que está enteramente sometido al primer patrón y, dentro de éste, tan sólo admite o contempla una vía de dirección única. La razón no es otra que la presión que en el diagrama ejerce el "modelo mozarabista o rupturista”, que a mi entender ha empezado a acusar el mismo defecto que el arqueólogo ha denunciado en el contrario "visigotista o continuista", a saber: que el modelo mismo "se ha independizado" de tal forma del investigador, que "actúa de modo previo sobre nuestra investigación imprimiendo su carácter, en el mejor de los casos, y forzando, en el peor, nuestras interpretaciones" ${ }^{90}$. La reciente traslación a "época emiral" del conjunto decorativo de Villajoyosa privilegiando o hacien-

\footnotetext{
${ }^{90}$ Caballero, "La arquitectura denominada...", pp. 207-248 (208).
} 
do prevalecer el argumento formal (la supuesta "raíz siria omeya" de estucos y mosaicos) por encima del arqueológico (ninguno de los materiales allí exhumados va más allá del siglo VI) me parece un ejemplo paradigmático de lo que digo ${ }^{91}$. Es cierto que la 'ausencia de pruebas' arqueológicas no 'prueba la ausencia' de vida más allá de la sexta centuria y que la conjetura que Caballero plantea es justa y apropiada, pero también que en la trastienda de su formulación se halla la necesidad de corroborar el "modelo mozarabista". El mapa se impone de esta manera sobre el territorio, el constructo sobre la realidad, y el sesgo de confirmación acaba sustituyendo al principio popperiano de falsación excepto en aquellos casos, curiosamente, en que lo que se pretende es desconfirmar el "modelo visigotista" ${ }^{92}$. Este vaivén entre refutación de A y corroboración de B es una trampa insalvable cuando lo que se pone en la palestra son dos teorías categóricas y radicalmente opuestas (donde B equivale de hecho a no-A) ${ }^{93}$.

El caso de la decoración de Pravia no me parece muy distinto del de Villajoyosa. A pesar de las limitaciones consustanciales al método formal $-\mathrm{y}$ que Caballero reconoce con honestidad ${ }^{94}$ — , el peso que la pauta de transmisión unidireccional tiene en

\footnotetext{
${ }^{91}$ Ib., pp. 219-225, y “Acerca del paisaje...", p. 266. Cf. la réplica de S. Gutiérrez Lloret, "Algunas consideraciones sobre la cultura material de las épocas visigoda y emiral en el territorio de Tudmīr", en Visigodos y Omeyas..., pp. 95-116 (105-110), y Uscatescu y Ruiz Souza, "El «occidentalismo»...", pp. 105-6.

${ }_{22}$ A la "falsación" alude Caballero en "Sobre límites y posibilidades de la investigación arqueológica de la arquitectura. De la estratigrafía a un modelo histórico", Arqueología de la Arquitectura, I (2002), pp. 83-I0o (85), como han visto Uscatescu y Ruiz Souza, “'Orientalismos'...”, p. 298. El "sesgo de confirmación" (confirmation bias) es un concepto usado por los científicos cognitivos para referirse a una amplia variedad de fenómenos cuyo denominador común es la tendencia a buscar, priorizar o interpretar la información que confirma nuestras hipótesis, deseos o creencias.

${ }^{93}$ Como dice Caballero, "las diferencias entre ambos [modelos] afectan, de una u otra manera, a todo el paisaje arquitectónico en el tiempo considerado" ("Acerca del paisaje...", p. 257), y “justamente el problema actual puede plantearse como el contraste entre las incompatibilidades de uno y otro modelo" ("La arquitectura denominada...", p. 211).

94 "Referencias y aparentes secuencias estilísticas no aseguran una correcta asignación cronológica, a lo más un encuadre amplio", lo que en Pravia se complica ante el inconveniente de "que apenas nos queda la traza de unos cimientos", hasta el punto de llevar al autor a confesar "la dificultad, si no la duda de las conclusiones a que llegamos" (Las iglesias asturianas..., p. 59).
}

su análisis de los canceles excluye de partida que se sopesen otra dinámicas alternativas de producción ornamental, mientras que la filiación formal con lo omeya se vuelve un factor tan determinante de la datación, que incluso se olvida un parámetro que en otros casos se habría considerado fundamental: la inexistencia de evidencias estratigráficas de la vinculación de las piezas escultóricas con la iglesia originaria ${ }^{95}$. Los canceles, en efecto, nos han llegado enteramente desgajados de la arquitectura, y en los escasos restos murarios y pavimentales del edificio prerrománico no se ha conservado ni una sola huella de su instalación. Nada impide pensar, por consiguiente, que hubiesen sido fabricados (en Pravia o cualquier otro lugar) hacia el año 900 con el objeto de sustituir otros más antiguos de tiempos del rey Silo; algo similar a lo que debió ocurrir en Santa Cristina de Lena ${ }^{96}$. Que en Santianes "su utilización lógica debe ser coetánea al edificio originario" 97 me parece una afirmación que como mínimo debe dejarse en cuarentena hasta que el resto de los indicios aducidos hasta el momento (historiográficos, epigráficos, arquitectónicos y ornamentales) no se amplíen, robustezcan o integren en un armazón más resistente a los embates de la refutación. Lo que no quiere decir que no me parezcan procedentes. Naturalmente, lo son, y por eso me interesa dejar bien claro que, a pesar de todo lo dicho, no descarto ni mucho menos que Santianes se hubiese podido construir "a las puertas del siglo X", como tampoco recuso la posibilidad de que el laberinto de Silo fuese un amaño del obispo Pelayo (o de los propios vecinos de Pravia unos decenios antes del pleito con la familia de Salas), o incluso una pieza original destinada inicialmente al palacio —y no a la iglesia — de Pravia (hipótesis que no me consta que haya sido planteada). Mi propósito, sen-

\footnotetext{
${ }^{95}$ Ya lo apuntan, aunque sea de pasada, Uscatescu y Ruiz Souza, "El «occidentalismo»...", p. 99.

${ }^{96}$ Sobre cuyos canceles hay disenso en cuanto a la cronología, pero sin que nadie discuta su evidente reutilización (cf. García de Castro, Arqueología cristiana..., pp. I52-5).

${ }^{97}$ Caballero, Las iglesias asturianas..., p. 50.
} 
cilla y abiertamente, ha consistido en tratar de demostrar que la nueva adscripción cronológica de la iglesia está basada en argumentos y pruebas todavía muy discutibles y, por ahí, que la inscripción del rey Silo debe seguir considerándose el indicio más fiable que por ahora tenemos de su fecha de construcción, aún a sabiendas de que ya no se trata $-y$ la precisión es importante- de la prueba irrefutable en que lo había convertido la historiografía tradicional.

Volviendo al ámbito estrictamente epigráfico, no querría cerrar este artículo sin plantear otro tema que puede resultar de interés. Coincido con García de Castro en que las tres inscripciones de Santianes son coetáneas y de la misma mano. No es sólo que el trazo de las letras sea idéntico; también lo es "la perfección de la labra, la elegancia de los tipos, el ajuste perfecto de los renglones y las distancias entre caracteres", hasta el punto de que su autor merece, en efecto, la calificación "de regio" ${ }^{9}$. La habilidad del lapicida es admirable: en el laberinto, el módulo de las letras tiende ligeramente al cuadrado para compaginar mejor con el diseño en damero del campo epigráfico, mientras que, en el epígrafe fundacional, las tres palabras más nobles — sacris (1. 3), Dei (1. 5) y Sion (1. 6) - tienen la interletra suavemente ensanchada con el claro propósito de realzarlas visualmente y engrandecer así su significado, un recurso, por cierto, que ya hemos visto en las inscripciones de Fávila y Wímara. Pues bien, si admitimos que el terceto es un grupo unitario y mantenemos su adscripción al rey Silo, resulta que en la iglesia Santianes nos topamos con el primer programa epigráfico de la Espańa medieval, entendiendo por 'programa' toda serie integrada de inscripciones concebidas a un tiempo o en el marco de un mismo proyecto por un mismo autor (o promotor) para un único edificio o complejo arquitectónico, a la manera de los famosos ciclos epigráficos que Paulino de Nola escribió para San Félix de Cimitile y el conjunto basilical de Sulpicio Severo en

\footnotetext{
${ }^{98}$ Arqueología cristiana..., p. I09. Buenas fotografías para la comparación, en IMA I75-7 y Arbeiter y Noack-Haley, Hispania Antiqua..., lám. $8 \mathrm{~b}-\mathrm{d}$.
}

su villa de Primuliacum ${ }^{99}$. El dato es significativo en la medida en que este tipo de programas suelen revelar una particular ambición epigráfica (mayor o distinta de la que deja entrever la inscripción aislada encargada de forma ocasional) o, por lo menos, una percepción más amplia de las posibilidades expresivas y simbólicas de la epigrafía monumental, más allá de sus funciones puramente comunicativa y conmemorativa. Son ciclos en que las inscripciones están conceptualmente coordinadas entre ellas y plenamente integradas en la arquitectura, en la que ocupan lugares precisos que determinan la forma y contenido del texto y desde los que contribuyen a articular y demarcar el espacio sagrado. Si tratamos de imaginarlo en su estado original, veremos que en el pequeño ciclo de Santianes no hay nada dejado al azar. Las tres inscripciones se concatenaban en la mitad oriental del edificio, en línea con el eje longitudinal de la iglesia y en reveladora consonancia con la triple división del santuario otrora decretada en los concilios toledanos ("sacerdos et levita ante altare conmunicent, in choro clerus, extra chorum populus") ${ }^{100}$ : expuesta a la asamblea en el umbral del coro y centro asimismo geométrico del edificio, se exhibía el delicado y sibilino laberinto, cuyos infinitos itinerarios de lectura, del centro hacia los vértices, evocaban el jardín del Edén, con sus cuatro ríos corriendo eternamente hacia los puntos cardinales, y mostraban — literalmente - que toda aquella iglesia, hasta sus cuatro esquinas, emanaba del príncipe Silo; un tramo más adelante, enclavada ya en el espacio reservado al clero, pero a la vista igualmente del "pueblo", campeaba sobre el arco triunfal del sancta sanctorum la inscripción fundacional o votiva, donde los propios autores de la domus dicata expresaban la esperanza de ser acogidos en Sión; y al fondo del locus terribilis, abrazando e

\footnotetext{
99 Un ensayo de definición general, con más ejemplos y bibliografía, en Rico, "Arquitectura y epigrafía...", pp. I2-4 y 27-8.

${ }^{100}$ IV Concilio de Toledo, canon I8, según J. Vives, Concilios visigóticos e hispano-romanos, Barcelona y Madrid, p. 298, tripartición celebrada más tarde en el prefacio poético del Antifonario de León, fols. 2v-3 (ed. L. Brou y J. Vives, Antifonario visigótico mozárabe de la catedral de León Barcelona, 1953-I959, p. 5).
} 
iluminando el altar desde la ventana axial, se honraba el nombre - y, con él, la presencia — del santo titular de la iglesia.

Si este triple diálogo entre arquitectura y epigrafía, tan meditado y bien enhebrado, fue obra, verdaderamente, del rey Silo, estaríamos ante un testimonio muy temprano - recordemos que el monarca falleció el año 783 - del despertar de una práctica epigráfica que en los reinos de esta parte del Mediterráneo había empezado a menudear en el siglo VII y que en el tercer cuarto del siglo VIII casi se había desvanecido por completo. Los escasos programas epigráficos que preceden al de Santianes en aquella centuria los encontramos en la Italia de Liutprando, uno de los pocos reyes del momento que supo ver "the potential of inscriptions as a means of propagating the ideology of a unified and Christian regnum under his rulership"101. Tan exiguo panorama empezó a cambiar, precisamente, en tiempos del rey Silo, prácticamente en el curso de una generación y gracias, en gran medida, a la influencia cultural que en aquellas fechas ejerció Pablo Diácono tanto en la corte longobarda como en la carolingia. Para el príncipe de Benevento Arechis II (774-787), el autor de la Historia Longobardorum compuso un poema de 32 hexámetros dactílicos celebrando la construcción de los muros de la ciudad de Salerno sobre el que se ha sugerido la posibilidad de que llegase a reproducirse en piedra, así como dos tituli métricos para la capilla del palatium salernitano —uno de ellos parcialmente conservado- y el epitafio catedralicio del propio príncipe $^{102}$. Y en su Gesta Episcoporum Mettensium, Diácono mismo nos cuenta que Carlomagno, a raíz de la muerte de su segunda mujer Hildegarda en 783,

\footnotetext{
${ }^{101}$ Everett, Literacy in Lombard Italy..., p. 275. Un "un ciclo epigrafico unitario, sia sul piano dei contenuti che su quello dell'elaborazione grafica", de tiempos de Liutprando, lo constituyen las cuatro inscripciones que conmemoraban la reconstrucción en el año 729 de la iglesia de Santa Mustiola en Chiusi (Siena) por iniciativa del duque Gregorio, seguramente el nieto del propio rey que más tarde sería duque de Benevento (cf. V. Cipollone y M. De Martino, "Note per una prima sistemazione del materiale epigrafico altomedievale di Chiusi: le 'tavole longobarde' della chiesa di Santa Mustiola”, en C. Fulluomini (ed.), Goti e longobardi a Chiusi, Chiusi, 2009, pp. 43-53).

${ }^{102}$ Cf. Lambert, "La produzione epigrafica..., pp. 292-5.
}

le había encargado una coherente serie de hasta cinco epitafios destinados a ornar las tumbas de dos de sus hermanas, de la propia Hildegarda y de dos de sus hijas, todas ellas enterradas en la abadía de SaintArnould de Metz ${ }^{103}$.

Los ciclos de Salerno y Metz me parecen los dos precursores más destacados del renacimiento que viviría la epigrafía latina en torno al año 800 en los territorios del imperio de Carlomagno y que encontraría a uno de sus mejores y más cabales artífices en el prolífico Alcuino ${ }^{104}$. La autoría de Pablo Diácono los inscribe a ambos en un mismo universo cultural y los coloca claramente en el albor del florecimiento epigráfico carolingio. Por contra, el logro equiparable y coetáneo de Santianes - logro, sobre todo, por su calidad técnica, variedad tipológica y carácter programático- se nos presenta, en principio, aislado y sin repercusión inmediata: la única inscripción conservada que puede datarse en tiempos del rey Silo es el humilde, lejano y problemático monumentum aedificationis de la ermita de las santas Centola y Elena de Siero (al norte de Burgos), fechado aparentemente en el año $777^{105}$; $y$, aunque sabemos que

${ }^{103}$ Cf. MGH SS, II, pp. 265-7, y Treffort, Mémoires carolingiennes..., pp. 229-23I.

${ }^{104}$ En el ámbito de lo que me gusta llamar 'programas epigráficos', el poeta de York no tuvo parangón entre sus contemporáneos, como muestra la docena larga de colecciones de epigramas que compuso para algunas de las abadías más importantes de su época. Cf. F. Stella, "Epigrafia letteraria e topografia della vita quotidiana dei monasteri carolingi", en F. De Rubeis y W. Pohl (eds.), Le scritture dai monasteri. Atti del II ${ }^{o}$ Seminario Internazionale di Studio "Imonasteri nell'Alto Medioevo", Roma 9-10 Maggio 2002, Roma, 2003, pp. 123-144, y C. Treffort, "La place d'Alcuin dans la rédaction épigraphique carolingienne", Annales de Bretagne et des Pays de l'Ouest, 111 (2004), pp. 353-369.

${ }^{105}$ El problema de esta inscripción, con el nombre de los promotores del edificio, signo de validación y la fecha, no se halla tanto en la lectura de ésta última - claramente E[RA DCCC]XV, aunque se han sugerido variantes para la cifra final que tampoco nos conducirían más allá del año 792-, como en las interpretaciones que ha suscitado el hecho de que esté repicada. Mientras J. A. Fernández Flórez entrevé la corrección posterior de una data más primitiva — con sólo dos C — que situaría el edificio en 677 (La elaboración de los documentos en los reinos hispánicos occidentales (ss. VI-XIII), Burgos, 2002, pp. 42-3), L. Caballero imagina un error del lapicida y el consiguiente repentir que le habría llevado a borrar la fecha ex profeso, dado que la datación en el siglo VIII le parece "demasiado antigua para admitir que su temática decorativa [una esquemática cepa de vid con racimos] sea una evolución de la de Quintanilla si esta iglesia se considera de reconquista y se data poco antes de 900" ("Un canal de transmisión...", p. II6). Sin embargo, como ha señalado recientemente Castresana López, nadie ha valorado el significativo dato de que, en los ańos 30 del siglo XX, 
unos decenios después Alfonso II encargaría más inscripciones que cualquiera de los monarcas que lo habían precedido, la aparición en Asturias de cierto 'hábito epigráfico' fuera del ámbito de la realeza no se comienza a percibir sino justo después de su fallecimiento en 842 , como espero explicar en otra ocasión. Habría que preguntarse, en consecuencia, si el programa de Santianes se debió de alguna manera a cierta apertura de la corte de Pravia hacia el exterior $y$, en particular, hacia la cultura carolingia, justo en el momento previo al estallido (y pronta resonancia internacional) de la polémica adopcionista.

Es posible, aunque tampoco rigurosamente necesario. La dinámica epigráfica también admite las dos pautas creativas evocadas unos párrafos más arriba - los 'canales de transmisión' y las invenciones independientes sobre tradiciones compartidas-, y no debemos olvidar que toda la epigrafía europea del siglo VIII se nutrió, al igual que la decoración escultórica, de un sustrato común tardoantiguo. Además, el ciclo epigráfico de Santianes pudo ser un ave solitaria dentro del género epigráfico, pero fue parte inseparable de la nueva andadura literaria y cultural que Díaz y Díaz observó en la Asturias de la segunda mitad del siglo VIII, la que reflejan tres composiciones de calidad desigual, pero novedosas en el contexto en que se produjeron y muy próximas en el tiempo al rey Silo, como son el poema acrotelésico del obispo Ascárico, el epitafio literario del abad Ildemundo y el poema litúrgico en honor de Santiago, obras las tres, dicho sea de paso, que ponen en escena distintas variantes de acróstico, una técnica diferente del laberinto de Pravia, pero con el que comparte el gusto por la escritura artificiosa y visual ${ }^{106}$. Esta etapa de desarrollo y enriquecimiento cultural debe asociarse tanto a la proliferación de pequeñas comunidades monásticas, algunas de los cuales propiciarían la aparición de escritores de

la última línea de la inscripción estaba tapada por un enlucido, de modo que el deterioro pudo producirse durante el proceso de desencalado (Corpus inscriptionum..., pp. 520-I).

${ }^{106}$ Cf. Díaz y Díaz, Asturias..., pp. 95-IO2 y 153-6, y los respectivos capítulos dedicados a cada una de estas piezas. cierto empaque como Beato y Eterio (ambos, por cierto, asistentes en la toma de velo de la reina viuda Adosinda el 26 de noviembre de 785), como a la llegada a las comarcas asturianas de nuevas gentes procedentes de las regiones conquistadas en tiempos de Alfonso I. Con ellas se introdujeron en Asturias nuevos intereses y nuevos materiales de inspiración, quizá no muchos y arraigados todos en la tradición hispano-visigoda, pero suficientes para que se empezase a crear ese "mundo distinto y nuevo"107 que representan el caligrama de Silo y el acróstico jacobeo. La presencia de los poemas de Ascárico e Ildemundo en la llamada Anthologia Hispana, justo al final de un núcleo homogéneo de piezas en que dominan los epitafios hispanos, sugiere la circulación por Asturias de colecciones poéticas de estilo similar ${ }^{108}$. El manuscrito parisino, además de completarse con obras selectas de Sedulio, Venancio Fortunato o Eugenio de Toledo, material que habría bastado — decía también Díaz y Díaz- para componer la lápida de Fávila, incorpora el pequeño ciclo epigráfico que Martín de Braga compuso para la sede episcopal de Dumio y otros tres epigramas que podrían asimismo haber pertenecido a un mismo santuario, esta vez hispalense ${ }^{109}$. El programa de Santianes pudo perfectamente concebirse a partir de modelos parecidos, incluido el laberinto -me apunta Isabel Velázquez con razón-, pues el propio Venancio Fortunato fue aficionado a componer carmina figurata más complejos que el asturiano, pero basados en el mismo sistema de letras cruzadas ${ }^{110}$. Escudriñando en alguna antología poética, sin lu-

\footnotetext{
${ }^{107} \mathrm{Ib}$., pp. I53-4.

${ }^{108}$ París, Bibl. Nat. lat. 8093, fols. I5-16. Cf. M. Vendrell Peñaranda, "Estudio de los códices de la Biblioteca Nacional de París, ms. 8093, y de la Biblioteca Universitaria de Leiden, ms. Voss. F II", Helmantica, XLIII (1992), pp. I47-20I, y las atractivas ideas de Díaz y Díaz sobre su posible 'prehistoria', en Asturias..., pp. 62 y 154.

${ }^{109}$ Cf. más detalles en Rico, "Arquitectura y epigrafía...", pp. I4-2I.

${ }^{110}$ Véase, en particular, Crux mihi certa salus..., un dístico elegíaco en forma de cruz donde cada brazo lo ocupa un hemistiquio que se lee de dentro a fuera, por múltiples vías, a partir de la palabra crux, colocada en el centro y diseñada de la misma manera que "Silo" en la piedra de Santianes (con la progresiva repetición de las sucesivas letras en múltiplos de 4 y su disposición en rombo). Cf. M. Reydellet (ed.), Venance Fortunat. Poèmes, I, Livres1-IV, París, 2002, p. 56, y Higgins, Pattern Poetry..., pp. 35-7 y fig. 2.I2a.
} 
gar a dudas, pero también en las viejas inscripciones visigodas que a buen seguro se fueron descubriendo a medida que se pacificaban y repoblaban las regiones excéntricas del reino astur. Es lo que ocurrió en tiempos de Fruela I cuando el abad Argerico y su hermana Sara, procedentes "de finibus Spanie", llegaron al antiguo monasterio de Samos, en tierras lucenses, con el mandato regio de reconstruirlo y colonizar los alrededores. Allí se encontraron con una larga inscripción del obispo de Lugo Ermefredo - documentado en los concilios toledanos de 653 y 656-, escrita a dos columnas y todavía recordada casi dos siglos después por Ordoño II (914-924) cuando ordenó restaurar de nuevo "ipsam baseligam sub monastica religione (...) sicut ex antiquo fuerat, quomodo ibi scriptum resonat in illa petra: Gaudeat acceptum hic (...). Per hec quod novimus quia Cenovialem claruit ibi decus"111. El mismo diploma del rey leonés es el que nos informa de la estancia en Samos de Alfonso II cuando aún era niño ("adhuc in pueritia"), con el fin de resguardarse de los enemigos de su padre ("in tempus persecutionis eius”). No es casual que la primera inscripción asturiana grabada a dos columnas de la que tenemos noticia sea ni más ni menos que la lápida del altar ovetense de San Salvador ${ }^{12}$.
111 Carta de dotación del monasterio de Samos por Ordońo II, el i de agosto de 922 (E. Flórez, España Sagrada, I4, Madrid, I796, pp. 274-5). La restauración de Argerico la confirman otros documentos del Tumbo de Samos fechados en 8II y 853 (cf. "San Xulián de Samos. Unha instancia de poder na Idade Media”, en M. C. Folgar de la Calle y A. Goy Diz (dirs.), San Xulián de Samos: Historia e arte nun mosteiro, Santiago de Compostela, 2008, pp. 49-72, espec. 50-I). El texto de la inscripción, aparecida en $\mathrm{I753}$, pero perdida con la exclaustración, lo reconstruye en la medida de lo posible A. Mundó, "La inscripción visigoda del monasterio de Samos", Studia Monastica, 3 (196I), pp. I57-I64.

112 Recordemos la descripción del Liber Testamentorum: "Haec scriptura a parte altaris sancti Saluatoris dextera et sinistra invenitur lapidibus scripta" (ut supra, n. 40). 